\title{
Global distribution of Earth's surface shortwave radiation budget
}

\author{
N. Hatzianastassiou ${ }^{1,2}$, C. Matsoukas ${ }^{2,3}$, A. Fotiadi ${ }^{2}$, K. G. Pavlakis ${ }^{2,5}$, E. Drakakis ${ }^{2,4}$, D. Hatzidimitriou ${ }^{2,3}$, and \\ I. Vardavas ${ }^{2,3}$ \\ ${ }^{1}$ Laboratory of Meteorology, Department of Physics, University of Ioannina, Greece \\ ${ }^{2}$ Foundation for Research and Technology-Hellas, Heraklion, Crete, Greece \\ ${ }^{3}$ Department of Physics, University of Crete, Crete, Greece \\ ${ }^{4}$ Department of Electrical Engineering, Technological Educational Institute of Crete, Greece \\ ${ }^{5}$ Department of General Applied Science, Technological Educational Institute of Crete, Greece
}

Received: 5 July 2004 - Published in Atmos. Chem. Phys. Discuss.: 11 July 2005

Revised: 7 October 2005 - Accepted: 13 October 2005 - Published: 1 November 2005

\begin{abstract}
The monthly mean shortwave (SW) radiation budget at the Earth's surface (SRB) was computed on 2.5degree longitude-latitude resolution for the 17-year period from 1984 to 2000, using a radiative transfer model accounting for the key physical parameters that determine the surface SRB, and long-term climatological data from the International Satellite Cloud Climatology Project (ISCCPD2). The model input data were supplemented by data from the National Centers for Environmental Prediction National Center for Atmospheric Research (NCEP-NCAR) and European Center for Medium Range Weather Forecasts (ECMWF) Global Reanalysis projects, and other global data bases such as TIROS Operational Vertical Sounder (TOVS) and Global Aerosol Data Set (GADS). The model surface radiative fluxes were validated against surface measurements from 22 stations of the Baseline Surface Radiation Network (BSRN) covering the years 1992-2000, and from 700 stations of the Global Energy Balance Archive (GEBA), covering the period 1984-2000. The model is in good agreement with BSRN and GEBA, with a negative bias of 14 and $6.5 \mathrm{Wm}^{-2}$, respectively. The model is able to reproduce interesting features of the seasonal and geographical variation of the surface SW fluxes at global scale. Based on the 17year average model results, the global mean SW downward surface radiation (DSR) is equal to $171.6 \mathrm{Wm}^{-2}$, whereas the net downward (or absorbed) surface SW radiation is equal to $149.4 \mathrm{Wm}^{-2}$, values that correspond to 50.2 and $43.7 \%$ of the incoming SW radiation at the top of the Earth's atmosphere. These values involve a long-term surface albedo equal to $12.9 \%$. Significant increasing trends in DSR and net DSR fluxes were found, equal to 4.1 and $3.7 \mathrm{Wm}^{-2}$, respectively, over the 1984-2000 period (equivalent to 2.4 and
\end{abstract}

Correspondence to: N. Hatzianastassiou

(nhatzian@cc.uoi.gr)
$2.2 \mathrm{Wm}^{-2}$ per decade), indicating an increasing surface solar radiative heating. This surface SW radiative heating is primarily attributed to clouds, especially low-level, and secondarily to other parameters such as total precipitable water. The surface solar heating occurs mainly in the period starting from the early 1990s, in contrast to decreasing trend in DSR through the late 1980s. The computed global mean DSR and net DSR flux anomalies were found to range within \pm 8 and $\pm 6 \mathrm{Wm}^{-2}$, respectively, with signals from $\mathrm{El}$ Niño and $\mathrm{La}$ Niña events, and the Pinatubo eruption, whereas significant positive anomalies have occurred in the period 1992-2000.

\section{Introduction}

Knowledge and monitoring of the Earth's radiation budget (ERB) is essential for improving our understanding of the Earth's climate and potential climatic changes (IPCC, 2001), since the radiative energy exchanges at the top of the atmosphere (TOA) and at the Earth's surface regulate the redistribution of energy and determine the energy balance of the Earth-atmosphere system. Rather than examining ERB as a whole, it is very important to quantify its components, namely the Earth's radiation budget at TOA (TOARB), within the atmosphere, and at the surface (SRB). Satellite observations, such as those from Nimbus-7 and the Earth Radiation Budget Experiment (ERBE) have greatly improved our knowledge of TOARB. Nevertheless, at present time, knowledge of SRB is far less advanced than the one for TOARB. The SRB, however, is a major component of the energy exchanges between the atmosphere and the land/ocean surface, and hence affects temperature fields, atmospheric and oceanic circulation, and the hydrological cycle. Besides, SRB data constitute a valuable resource for initialising

(C) 2005 Author(s). This work is licensed under a Creative Commons License. 
and testing climate and general circulation models (GCMs). The estimation of SRB represents one of the most significant objectives of the World Climate Research Programme (WCRP) as demonstrated by its Global Energy and Water Cycle Experiment (GEWEX), and in particular the GEWEX SRB project (Stackhouse et al., 1999; Gupta et al., 1999).

The global distribution of SRB cannot be derived from surface observations because of the sparsity and nonhomogeneity of stations ( $\mathrm{Li}$ and Leighton, 1993; Li et al., 1997), especially over oceans. Thus, global atlases from surface-based observations (Esbensen and Kushnir, 1981) suffer from this shortcoming. Therefore, the modelling approach remains as the only alternative, provided that the model results can be trusted through validation against quality measurements. One way to solve the problem is to establish correlations between TOA and surface radiative fluxes in order to derive surface fluxes directly using the satellite measurements of TOA fluxes (for example, Ramanathan, 1986; Schmetz, 1989; Weare, 1989; Cess et al., 1991; Darnell et al., 1992; Pinker and Laszlo, 1992; Li and Leighton, 1993). However, there is uncertainty regarding the reliability of the correlations used to produce surface SW fluxes (Gupta et al., 1999). Another way to solve the problem of estimating SRB is to develop algorithms and models to compute SRB fluxes on a global scale using observations of atmospheric, cloud, and surface properties, preferably from operational satellite sources to provide global coverage. Recently, the amount and quality of satellite data have substantially improved, especially in terms of clouds (whose some properties, such as cloud optical depth, represented the most difficult parameters to be derived for many years) with the International Satellite Cloud Climatology Project (ISCCP, Rossow and Schiffer, 1991) that provides the most complete and comprehensive existing global cloud climatology. In the last two decades, a large number of studies estimating SRB have been published (e.g. Raschke et al., 1987; Darnell et al., 1988; Rossow and Lacis, 1990; Kyle at al., 1990; Stephens and Greenwald, 1991; Darnell et al., 1992; Hartmann, 1993; Li and Leighton, 1993; Kiehl et al., 1995; Rossow and Zhang, 1995; Whitlock et al., 1995; Fowler and Randall, 1996; Del Genio et al., 1996; Chen and Roeckner, 1996; Wild et al., 1998a, b; Yu et al., 1999). Gupta et al. (1999) derived a 8-year (July 1983-June 1991) climatology of SRB by using satellite data from the ISCCP C-series, on a monthly mean basis. Hatzianastassiou and Vardavas $(1999,2001)$ provided also an 8-year climatology of the SW radiation budget of the northern and southern hemispheres, respectively, but this was done only on a 10-degree latitude zonal and monthly mean basis. Furthermore, these studies have been performed by using data from the ISCCP-C2 series. The new ISCCP Dseries data include significant improvements, especially in terms of cloud structure and cloud detection over highly reflecting surfaces (cf. Rossow and Schiffer, 1999) and cover a longer time period, extending up to year 2000. This is important, since the Earth's radiation budget changes with time. Although the more recent energy budget studies, including those from GCMs, but also results from reanalysis projects (such as the National Centers for Environmental Prediction/National Center for Atmospheric Research, NCEP/NCAR, or the European Center for Medium Range Weather Forecast, ECMWF), show good agreement with observations at TOA, there is a considerable variation for $\mathrm{SW}$ SRB (called henceforth simply SRB) within about $20 \mathrm{Wm}^{-2}$ (Kiehl and Trenberth, 1997). Moreover, estimated surface SW flux values tend to be systematically higher than groundbased station observations by significant amounts (Garratt, 1994; Wild et al., 1995, 1998a, b; Li et al., 1997; Kiehl and Trenberth, 1997; Garratt et al., 1998; Wild, 2005). For example, the global and annual mean SW flux absorbed at the surface is generally larger than $170 \mathrm{Wm}^{-2}$, with the exception of the European Center/Hamburg (ECHAM) model, while the only direct radiative surface flux measurements from the Global Energy Balance Archive (GEBA, Ohmura and Gilgen, 1993), which constitutes the "best" estimate of the globally averaged net SW flux, indicates values that are lower by about $20-25 \mathrm{Wm}^{-2}$. Only recently, Zhang et al. (2004) using ISCCP-D1 data, produced 18-year DSR fluxes that are lower than $170 \mathrm{Wm}^{-2}$, in good agreement with both GEBA and BSRN measurements.

In this study we provide a 17-year (January 1984December 2000) climatology of the Earth's SRB, on a 2.5degree longitude-latitude resolution, and on monthly mean basis. A physical deterministic radiative transfer model is used to compute the SRB components, i.e. the SW downward surface radiation (DSR) and the net downward (or absorbed) SW radiation (called henceforth net DSR) at the Earth's surface. The model has been improved with respect to the versions used in previous studies (Hatzianastassiou and Vardavas, 1999, 2001), as explicitly described in Sect. 2. Nevertheless, note that in this study flux calculations are performed using ISCCP-D2 monthly mean input data sets. Because of the non-linear relationship between radiative fluxes and the input physical parameters of the model, monthly mean input-based "monthly mean fluxes" are not the same as the monthly-mean fluxes averaged from hourly/daily fluxes. However, this problem is alleviated by the fact that the ISCCP-D2 cloud properties are based on a radiatively linear average method, so that differences should be small. Note that there are available 3-hourly and decades-long flux datasets, also including DSR, namely GEWEX/SRB (Stackhouse et al., 2001) and ISCCP-FD (Zhang et al., 2004). Our model is also run using daily mean data at higher spatial resolution $\left(1^{\circ} \times 1^{\circ}\right.$ latitude-longitude). Extensive comparisons between the model results presented in this paper and those of higher spatial and temporal resolution, have shown very good agreement, with a correlation coefficient equal to $98.5 \%$. The daily mean model results cover a shorter period (10-year, 1985-1995) than the 17-year (1984-2000) period covered by the ISCCP-D2 data. 
Here, the seasonal and geographical variation of SRB components is investigated, with emphasis given to patterns of averaged values over space and time, specific local and temporal characteristics, and inter-annual variability. Climatological data for the surface and atmospheric parameters which are relevant to the transfer of SW radiation, were taken from existing complete global data sets. Data for clouds, but also for other surface and atmospheric parameters were taken from ISCCP-D2, supplemented by humidity and temperature data taken from NCEP/NCAR and ECMWF reanalysis projects. Model input data were also taken from other global data bases, such as the Television Infrared Observational Satellite (TIROS) Operational Vertical Sounder (TOVS), whereas aerosol particles were accounted for in the study, by using relevant data from the Global Aerosol Data Set (GADS), as explained in Sect. 3. The model computations are validated at the grid cell level against quality data from the Baseline Surface Radiation Network (BSRN) and GEBA. A brief description of the model is given in the next section, while Sect. 3 describes the model input data. The model results are given in Sect. 4, where patterns of seasonal and temporal distributions of SRB components are discussed on the basis of grid cell-level model results, while mean hemispherical and global, along with mean annual SRB results are given and inter-annual variations and trends are examined. Section 5 provides a sensitivity analysis of SRB components to the various key surface and atmospheric parameters. The results of the model validation at grid cell level against BSRN and GEBA stations are given in Sect. 6, before the summary and conclusions (Sect. 7).

\section{Model description}

The SW radiative transfer model used is described in detail in the work by Hatzianastassiou et al. (2004a), where it has been used to compute the top of atmosphere (TOA) SW radiation budget. It was developed from a radiative-convective model (Vardavas and Carver, 1984) and previous versions have been used by Vardavas and Koutoulaki (1995) and Hatzianastassiou and Vardavas $(1999,2001)$ to compute the SW radiation budget of northern and southern hemispheres on a mean monthly and $10^{\circ}$ latitude zonal basis. The model has been successfully tested (cf. Hatzianastassiou and Vardavas, 1999; 2001) according to the Intercomparison of Radiation Codes in Climate Models (ICRCCM) program, as well as against Earth Radiation Budget Experiment (ERBE) S4 scanner data (cf. Hatzianastassiou et al., 2004a).

In brief, the radiative transfer model divides the $\mathrm{SW}$ radiation into two spectral bands, one for the ultraviolet-visible (UV-visible) wavelengths $(\lambda<0.85 \mu \mathrm{m})$ accounting for about $60 \%$ of total solar radiation, and a second band for the near-infrared (near-IR) wavelengths $(0.85 \mu \mathrm{m} \leq \lambda \leq 5 \mu \mathrm{m})$ accounting for about $40 \%$ of total solar radiation. The model achieves a compromise between accuracy of spectral model computations and speed of computation of parameterisation schemes. The monthly mean incoming total solar flux at TOA for each 2.5-degree latitude-longitude grid cell, is computed theoretically, in the way explained in detail by Hatzianastassiou et al. (2004a). The computed incoming solar radiation at TOA for each month and 2.5-degree grid cell matches well the 5-year scanner S4 data from ERBE (model - ERBE differences within $2.5 \mathrm{Wm}^{-2}$, with uncertainty of ERBE fluxes equal to $6 \mathrm{Wm}^{-2}$ ). The solar radiative transfer in the Earth-atmosphere system is treated separately in the UV-visible and near-IR spectral bands and accounts for absorption and multiple scattering. The model takes into account the physical parameters and processes that affect significantly the solar radiation transfer: ozone $\left(\mathrm{O}_{3}\right)$, water vapour $\left(\mathrm{H}_{2} \mathrm{O}\right)$, carbon dioxide $\left(\mathrm{CO}_{2}\right)$, aerosol particles, Rayleigh scattering, surface reflection and non-overlapping clouds (low, middle and high-level). For each grid cell, the sky is divided into clear and cloudy fractions, and hence direct and diffuse components are considered for solar radiation. The transfer of solar radiation in the Earth-atmosphere system is treated separately for clear- and cloudy-sky atmospheric conditions, by taking into account the presence of the relevant surface and atmospheric parameters (for details see Hatzianastassiou et al., 2004a). The net incoming solar radiation at TOA (planetary absorption), $F_{\text {net,top }}^{\downarrow}$, the outgoing SW radiation (OSR) at TOA, $F_{\text {top }}^{\uparrow}$, and the planetary albedo $R_{p}$ and planetary absorptivity $\alpha_{p}$, are computed as in Vardavas and Koutoulaki (1995).

Both clear- and cloudy-sky (corresponding to low, middle and high-level clouds) components of $\alpha_{p}$ are computed by dividing the incoming solar radiation into UV-visible and near-IR components, based on estimated transmissivities, absorptivities, and reflectivities of the different atmospheric and cloud layers and the Earth's surface (see Vardavas and Koutoulaki, 1995; Hatzianastassiou and Vardavas, 1999, 2001). The reflectivity, transmissivity and absorptivity of each atmospheric layer, due to $\mathrm{O}_{3}, \mathrm{CO}_{2}$, water vapour, and Rayleigh scattering, are computed by using parameterisations derived from laboratory measurements (Vardavas and Koutoulaki, 1995).

For each cloud and aerosol layer, computations are performed using two-stream approximation for purely scattering clouds in the UV-visible, and a modified two-stream approximation allowing for cloud absorption in the near-IR (Vardavas and Koutoulaki, 1995; Hatzianastassiou and Vardavas, 1999) and for aerosol absorption in the UV-visible. For clear sky, Rayleigh scattering is taken into account by the model in the UV-visible, while it is neglected for the near-IR component, given that the Rayleigh scattering cross-section decreases rapidly with wavelength. For a cloudy sky, Rayleigh scattering is neglected since cloud optical depth is much larger than the Rayleigh scattering optical depth.

Reflection of incident solar radiation from the Earth's surface is taken into account and the surface reflectivity, $R_{g}$, 
for each 2.5-degree grid cell, is computed considering four general types of surface: land, ocean, snow and ice (frozen ocean). Then

$R_{g}=f_{\text {land }} R_{\text {land }}+f_{\text {ocean }} R_{o}+f_{\text {snow }} R_{s}+f_{\text {ice }} R_{i}$

where $f_{i}$ is the fractional coverage of the grid cell's surface by each type $-i$ of reflecting surface. The ocean reflectivity, $R_{o}$, is computed using Fresnel reflection corrected for a nonsmooth surface for an incident angle $\phi=\cos ^{-1} \mu$ from

$$
R_{o}=0.5\left[\left(\frac{\sin a}{\sin b}\right)^{2}+\left(\frac{\tan a}{\tan b}\right)^{2}\right]+0.016 \cos \varphi
$$

where

$a=\varphi-\sin ^{-1}[\sin \varphi / 1.333]$

$b=2 \varphi-a$

For incident solar radiation onto a perfectly smooth water surface, the angle of reflection equals that of incidence, and for normal incidence the reflectivity is 0.021 . For an ocean we correct the Fresnel reflectivity to take into account surface roughness, which leads to a higher surface reflectivity of about 0.04 for incident solar radiation normal to the water surface (Kondratyev, 1973). The correction factor $0.016 \cos \phi$ goes to zero when the radiation is parallel to the ocean surface in order to maintain a Fresnel reflectivity of unity in this case. Further, we include the condition that if Fresnel reflectivity is greater than ice- or snow reflectivity, which occurs for low solar elevations, then the reflectivities of ice or snow are set equal to the Fresnel one. Kuhn (1989) gives observations that clearly show this behaviour for snow cover in Antarctica.

Snow albedo, $R_{S}$, is set equal to 0.85 and 0.65 (Dickinson et al., 1993) in the UV-visible and near-IR, respectively, while sea-ice albedo, $R_{i}$, is set equal to 0.7 and 0.5 (Roesch et al., 2002) in the UV-visible and near-IR, respectively, based on recent estimates. Given that land shows a strong spatial variability in terms of its type and associated reflectance values, the data used were derived from ERBE data for clear sky, while overcast albedos were obtained by modifying the corresponding clear-sky values for diffuse radiation conditions (Darnell et al., 1992). Information for fractional coverage for each surface type (land, ocean, snow, ice) is obtained from ISCCP-D2 data (Rossow et al., 1996), whereas suitable reflectivity values for each surface type are ascribed, based on values taken from literature (Henderson-Sellers and Wilson, 1983; Briegleb et al., 1986), which allow for spectral dependence over the UV-visible and near-IR range of wavelengths, which is very important (Wei et al., 2001), but also allow for different values for the direct and diffuse components of solar radiation. A correction was applied to landsurface albedo for high-altitude mountainous areas such as Tibet, Rocky Mountains or Antarctica's plateau, consisting in a reduction of the albedo, in order to take into account the decrease of $R_{g}$ over mountainous non-forested areas, especially during winter, due to the sub-grid orography (Roesch et al., 2001).

The downward SW radiation at the Earth's surface (DSR) and the net downward (or absorbed) SW radiation at surface, are finally computed from the incoming SW radiation at TOA, $F_{\text {top }}^{\downarrow}$, in terms of an effective atmospheric transmissivity, $t^{*}$, with components $t_{s}^{*}$ and $t_{c i}^{*}$, for a clear-sky and cloudy sky covered by cloud type $-i$, respectively,

$D S R=t^{*} \cdot F_{t o p}^{\downarrow}$

where

$t^{*}=\left(1-A_{c}\right) \cdot t_{s}^{*}+\sum_{i} A_{c i} \cdot t_{c i}^{*}$

The effective atmospheric transmissivities $t_{s}^{*}$ and $t_{c i}^{*}$ are computed from estimated transmissivities of ozone, Rayleigh, water vapour, carbon dioxide, aerosols, and low, middle and high-level clouds, as well as reflectivities of surface, clouds and Rayleigh, as given by Vardavas and Koutoulaki (1995).

\section{The model data}

\subsection{Ozone, carbon dioxide and water vapour}

The mean monthly 2.5-degree latitude-longitude grid cell data of the total $\mathrm{O}_{3}$ column abundance (in Dobson Units) covering the years 1984-2000, were taken from TOVS, archived in the ISCCP-D2 package. For $\mathrm{CO}_{2}$ a fixed total atmospheric amount was taken, equal to $0.54 \mathrm{~g} \mathrm{~cm}^{-2}$, corresponding to 345 parts per million by volume (ppmv). The water vapour data used were taken from both the NCEP/NCAR and ECMWF Global Reanalysis Projects, which provide long-term climatological data. The layered data for specific humidity and atmospheric temperature were used to compute the total atmospheric water vapour content, $W_{\mathrm{H}_{2} \mathrm{O}}$. Relative humidity data were also used to compute the humidity of the aerosol layer. The differences, arising from the use of the two data sets, in terms of surface SW radiative fluxes were found to be small (mostly within $1-2 \mathrm{Wm}^{-2}$ at grid cell level), as discussed in Sect. 5. Therefore, in this study we only show DSR fluxes computed by using water vapour data taken from NCEP/NCAR Reanalysis.

\subsection{Clouds}

Mean monthly cloud properties on 2.5-degree equal-angle grid cell resolution for the study period (1984-2000) were taken from the latest D2 stage data of ISCCP (Rossow et al., 1996; Rossow and Schiffer, 1999). Cloud properties are provided from ISCCP for nine (9) cloud types which are grouped into three categories: low-level clouds having top pressures greater than or equal to $680 \mathrm{mbar}$, high-level clouds with top 
pressures less than 440 mbar and mid-level clouds in between (Rossow et al., 1996). Low-level clouds are considered to be $\mathrm{Cu}, \mathrm{St}$ and Sc clouds. The middle ones include Ac, As and $\mathrm{Ns}$, while $\mathrm{Ci}$, Cs and deep-convective clouds are considered as high-level clouds. High clouds are treated as cold clouds, while each of the above low and middle clouds are subdivided into liquid- or ice-phase clouds, resulting in 15 cloud types for which properties such as cloud cover, cloud optical thickness, cloud-top temperature and pressure, as well as liquid or ice water path are provided by ISCCP-D2. The values for the 15 independent cloud types were then appropriately averaged (see Hatzianastassiou and Vardavas, 1999) to yield data for low, mid and high-level clouds needed by our model. Note that in our study, the ISCCP-D2 individual cloud data are used, which are derived by using the visible/infrared (VIS/IR) analysis, rather than the low, mid and high-level cloud data, also provided by ISCCP-D2, which are derived by using the IR-only analysis. This was done because the combined VIS/IR analysis is superior to the IR-only during daytime (Rossow et al., 1996), and thus is more appropriate for SW radiation budget studies. The VIS/IR (individual) cloud data were found to dramatically improve the model results at both TOA and surface, in terms of comparison with ERBE-S4 satellite and BSRN and GEBA site measurements, respectively.

The total cloud cover fraction, $A_{c}$, is calculated from the sum of fractions, $A_{c i}$, for low, middle and high clouds

$$
A_{c}=\sum_{i} A_{c i}
$$

Cloud optical thickness values for low, mid, and high-level clouds were calculated from corresponding values for individual clouds, as described in Hatzianastassiou and Vardavas (1999). For the computation of the cloud SW transmissivity and reflectivity, the model also requires cloud absorption optical depth, $\tau_{c}^{a}$, cloud scattering optical depth, $\tau_{c}^{s}$, and cloud asymmetry parameter, $g_{c}$. ISCCP-D2 provides, however, $\tau_{c}^{s}$ only at the visible wavelength $0.6 \mu \mathrm{m}$. The $\tau_{c}^{s}$ (near-IR) and $\tau_{c}^{a}$ (near-IR) values were derived by using either Mie computations or existing parameterisations (Slingo, 1989; Ebert and Curry, 1992) for ISCCP-D2 liquid and ice clouds, by assuming the appropriate ISCCP-D2 cloud microphysics, as explained in detail by Hatzianastassiou et al. (2004a). The model required values of $g_{c}$, not provided by ISCCP, must differ between liquid and ice clouds (Liou, 2002). Thus, values of $g_{c}$ were computed separately for liquid and ice clouds, for both UV-visible and near-IR range of wavelengths, by using both Mie computations and parameterisations, as explained by Hatzianastassiou et al. (2004a). The computed $g_{c}$ values in the UV-visible are equal to 0.85 and 0.78 for liquid and ice clouds, respectively, while the corresponding values in the near-IR range are equal to 0.82 and 0.8 .
3.3 Rayleigh scattering, surface reflection and aerosol particles

Rayleigh scattering is considered in the model as described in Vardavas and Koutoulaki (1995). The surface reflection is computed with the model at each grid cell for each month in the period 1984-2000, by considering four types of surface: land, ocean, snow, and ice (frozen ocean). Information on spatial and temporal variation of the fractional coverage of the Earth's surface by each type, was taken from ISCCP-D2. The radiative effect of aerosols is computed with our model by using a modified two-stream approximation allowing for scattering and absorption in the UV-visible and near-IR ranges of wavelength. Our model requires aerosol optical properties, namely aerosol optical thickness (AOT), single scattering albedo $\left(\omega_{\text {aer }}\right)$, and asymmetry parameter $\left(g_{\text {aer }}\right)$. Currently, there is no data base providing such aerosol data for the whole study period 1984-2000 on a global scale. There are new satellite-based instruments (e.g. Moderate Resolution Imaging Spectro-Radiometer, MODIS, or Polarization and Directionality of the Earth's Reflectance, POLDER) performing accurate spectral aerosol measurements on a global scale, but they have only started their operation from year 2001. There are some AOT data for the whole period from the Global Aerosol Climatology Project (GACP), but without global coverage as they only cover the ocean areas. On the other hand, there are AOT data with global coverage from the Total Ozone Mapping Spectrometer (TOMS, Torres et al., 2002), but no $\omega_{\mathrm{aer}}$, and $\mathrm{g}_{\mathrm{aer}}$ data. New re-processed AOT data from TOMS, including $\omega_{\text {aer }}$ data, that will cover the period 1979-2000 will be released by NASA Goddard Space Flight Center (GSFC). In the meantime, as a first step, the model-required aerosol data were derived from the Global Aerosol Data Set (GADS, Koepke et al., 1997). GADS provides AOT, $\omega_{\text {aer }}$, and $g_{\text {aer }}$ data, at 61 wavelengths from 0.25 to $40 \mu \mathrm{m}, 27$ of which lie in the SW range, and for 8 values of relative humidity $(0,50,70,80,90,95,98$, and $99 \%$ ). Given the strong dependence of aerosol optical properties on ambient relative humidity, the original GADS properties were then re-computed in a realistic way, for actual relative humidity values for the aerosol layer, as explained in detail by Hatzianastassiou et al. (2004b) for each month in the period from January 1984 to December 2000. Subsequently, the computed values of aerosol optical properties were averaged into the UV-visible and near-IR ranges, weighted by the spectral distribution of the incoming solar flux (Thakaekara and Drummond, 1971). Note that there is uncertainty in terms of seasonal variation of the aerosol effect on DSR, due to the limitations of GADS, providing nominal aerosol optical properties for two seasons, i.e. winter and summer. A complete description of the treatment of aerosols in the model, as well as of GADS aerosol data, can be found in the work by Hatzianastassiou et al. (2004b). 

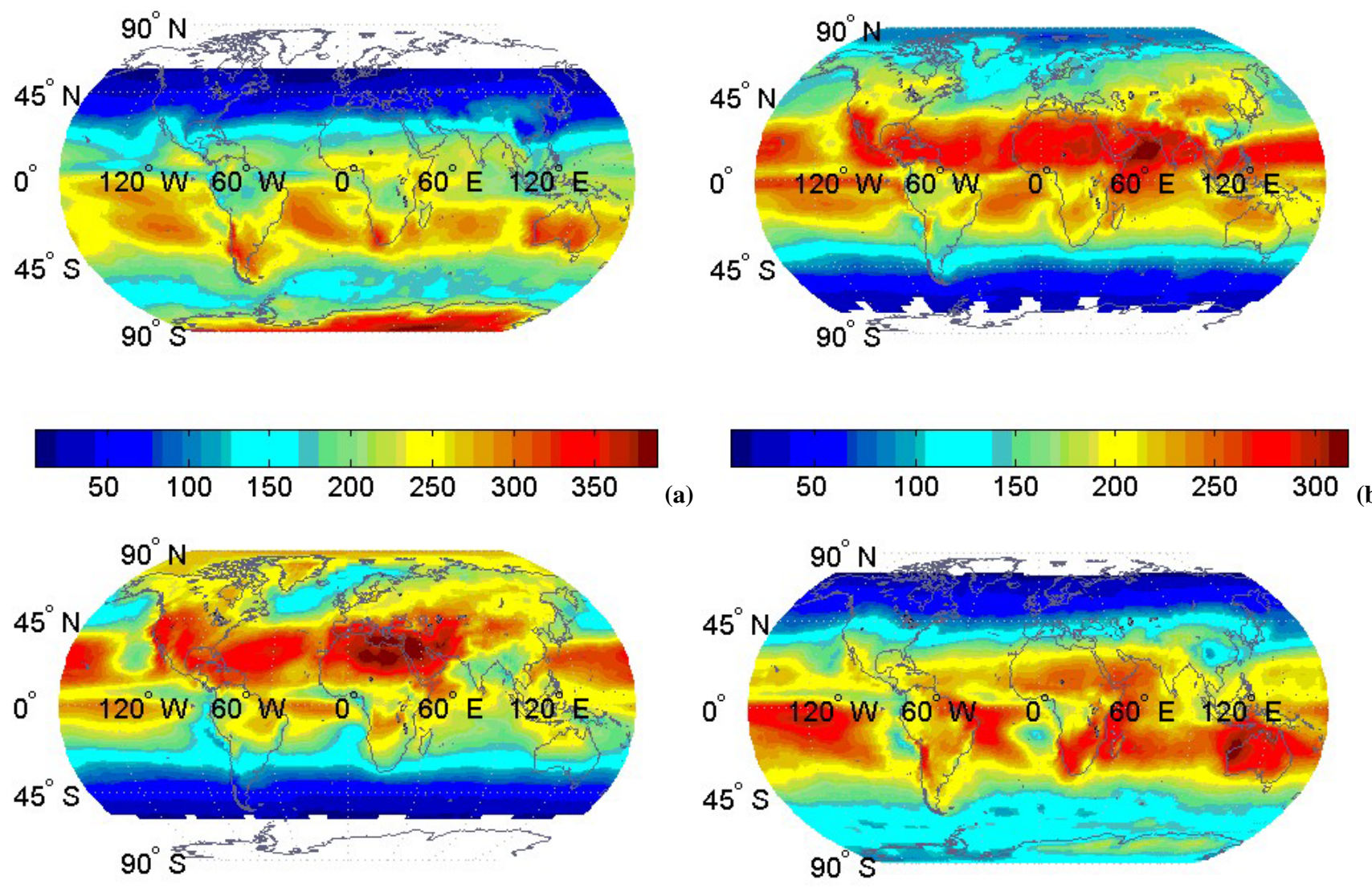

(b)

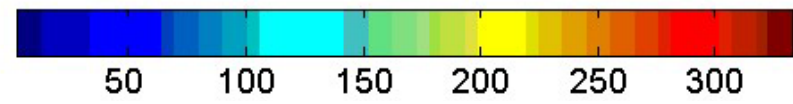

(c)

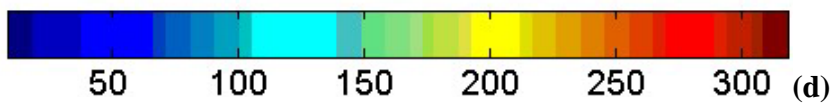

Fig. 1. Long-term (1984-2000) average global distribution of downward shortwave radiation (in $\mathrm{Wm}^{-2}$ ) at the Earth's surface for the mid-seasonal months of (a) January, (b) April, (c) July, and (d) October.

3.4 Cloud-top pressure, cloud physical thickness and surface pressure

The cloud-top pressure, $p_{c}$, and physical thickness, $d p_{c}$, both determine the atmospheric layer where water vapour absorption is replaced by cloud scattering and absorption. Values of $p_{c}$ were taken from ISCCP-D2 for low, mid, and highlevel clouds. The ISCCP-D2 does not provide $d p_{c}$ data, so these were estimated from Peng et al. (1982) for the Northern Hemisphere, as explained in the work by Hatzianastassiou and Vardavas (1999), while $d p_{c}$ values for Southern Hemisphere were estimated in the way described by Hatzianastassiou and Vardavas (2001), by combining the values from Peng et al. and those derived from Liou (1992). A complete topography scheme (which is important for regions with high altitude, such as the Tibetan plateau, Antarctica, Rocky or the Andes mountains) is included in the model, which uses surface pressure, $p_{s}$, data taken either from NCEP/NCAR or from ECMWF Global Reanalysis Projects gridded in $2.5^{\circ}$ by $2.5^{\circ}$ cells for each month of the 17-year period 1984-2000.

\section{Model results}

\subsection{Seasonal and geographical distributions}

The latitudinal gradient of the 17-year average downward SW radiation (DSR) at the Earth's surface is primarily determined by the incoming solar flux at TOA, while the patterns of longitudinal variation are mostly determined by cloud and surface properties. Therefore, large DSR fluxes are found in polar regions (Figs. 1a, c) during local summer, equal to about $300-350 \mathrm{Wm}^{-2}$ over Antarctica in January and 200 $250 \mathrm{Wm}^{-2}$ over the Arctic in July. Our values are lower than those given by Gupta et al. (1999), which are equal to 400$450 \mathrm{Wm}^{-2}$ in Antarctica and $250-300 \mathrm{Wm}^{-2}$ in the Arctic. Note, however, that Gupta et al. (1999) used ISCCP C-series 

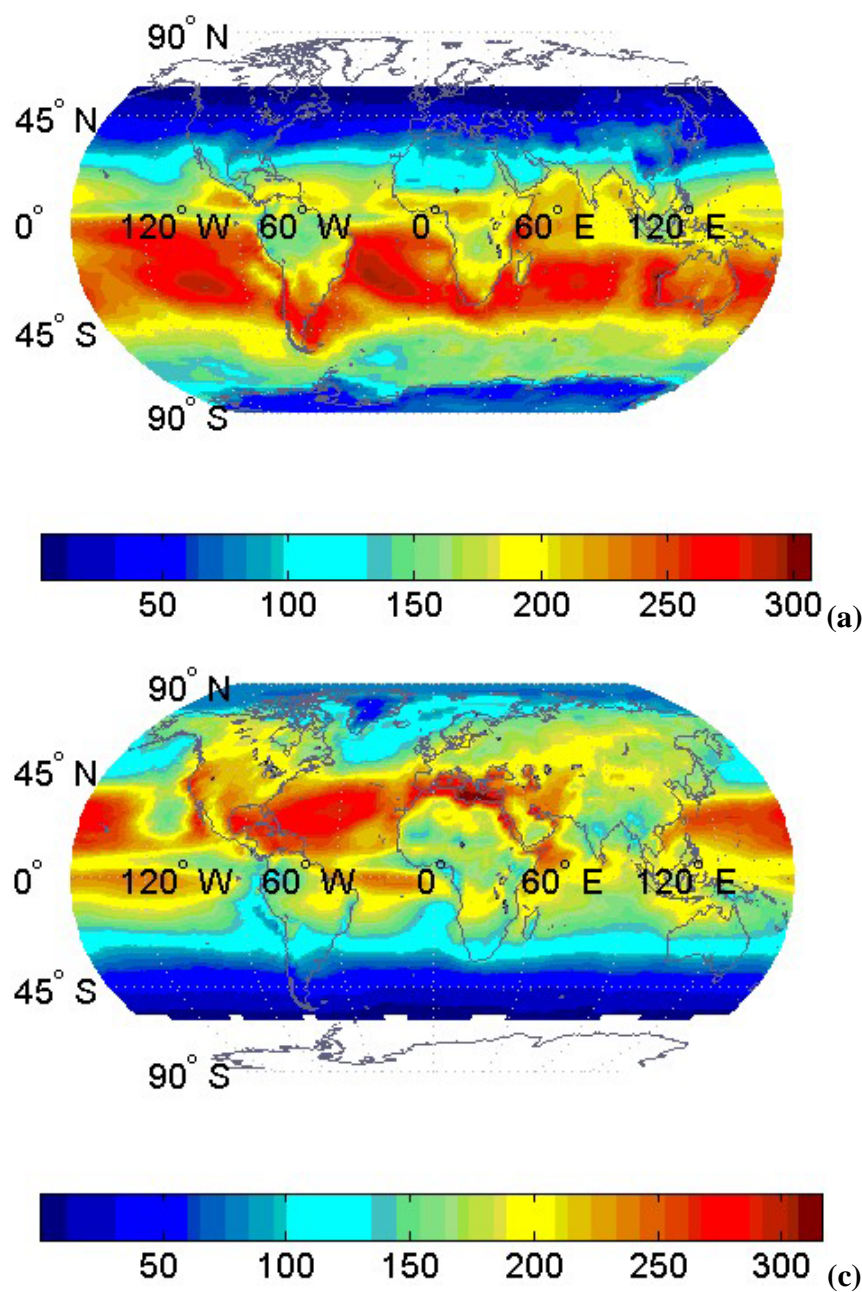
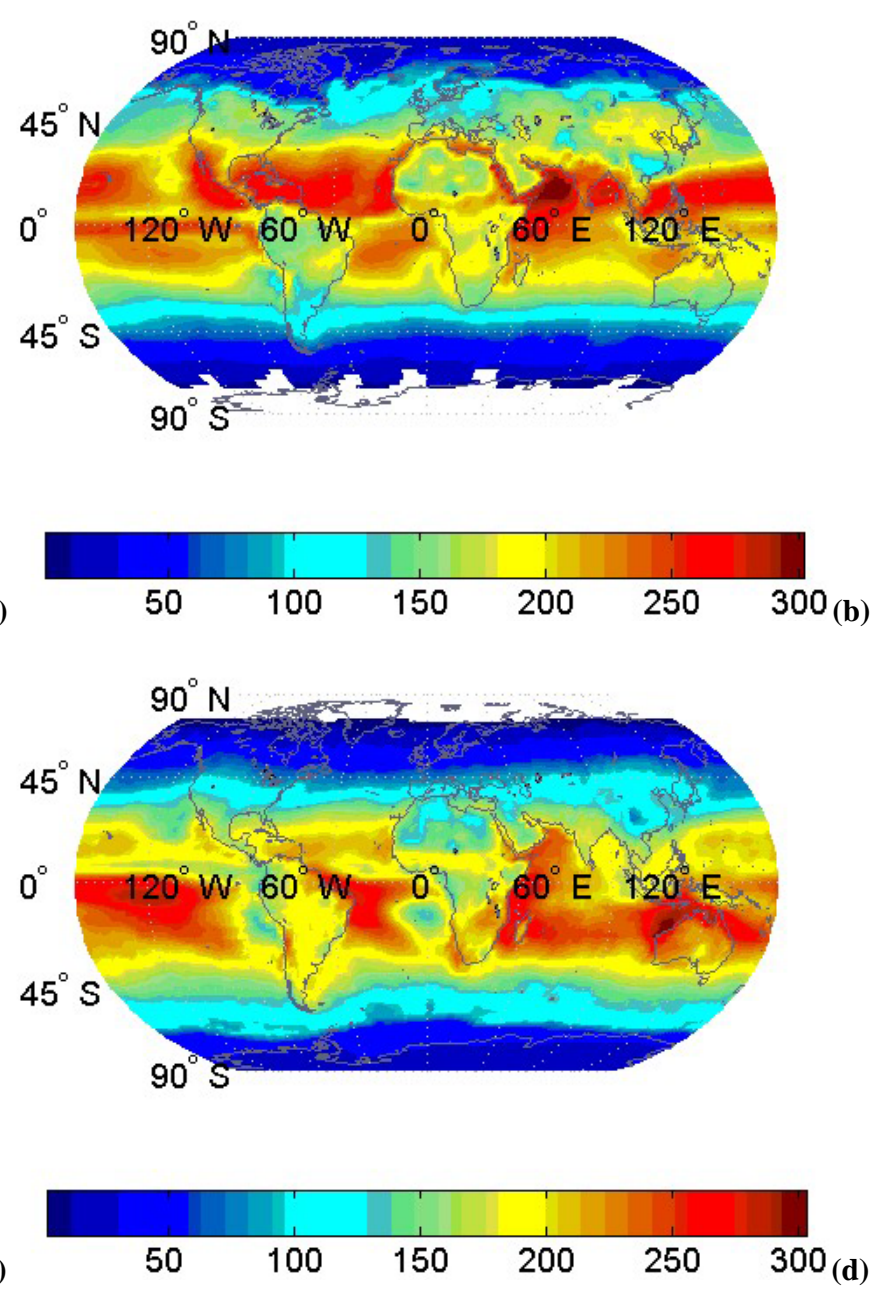

Fig. 2. Long-term (1984-1997) average global distribution of net downward (or absorbed) shortwave radiation (in Wm ${ }^{-2}$ ) at the Earth's surface for the mid-seasonal months of (a) January, (b) April, (c) July, and (d) October.

data to derive a 8-year (1983-1991) SRB against our 17-year (1984-2000) averages. The larger values over Antarctica than the Arctic are due to the larger incoming solar radiation at TOA during perihelion $\left(>500 \mathrm{Wm}^{-2}\right)$, but also to the smaller ISCCP-D2 summer cloudiness in Antarctica than in the Arctic ( $\approx 20 \%$ against $\approx 60 \%$, respectively). There is a gradual DSR decrease from the summer to winter pole in January and July, leading to zero values poleward of mid-tohigh latitudes. The white areas in Fig. 1 correspond to missing ISCCP model input data, but they do not affect our results since they coincide with polar night conditions. The latitudinal gradient of DSR is mitigated during spring and autumn (Figs. 1b, d). Overall, the DSR has maximum values over the subsidence regions associated with anticyclonic conditions and small cloud amounts, such as oceanic areas in low latitudes of the summer hemisphere, as well as over the polar areas of the summer hemisphere. In contrast, small DSR values are found over regions with large cloud amounts, such as the middle latitudes of the summer hemisphere. Thus, DSR values as low as $140 \mathrm{Wm}^{-2}$ are found over the stormtrack zone of southern hemisphere $\left(50^{\circ}-70^{\circ} \mathrm{S}\right)$ in January, whereas values down to about $100 \mathrm{Wm}^{-2}$ are computed in October. Corresponding features, with DSR values equal to $100-140 \mathrm{Wm}^{-2}$ in April and July, exist over northern Pacific Ocean's areas with large cloud amounts (equal to about 90\%). In general, there is a strong anti-correlation between DSR and cloud amount. Note the small DSR values off the western coasts of South America and South Africa in July, being smaller than corresponding DSR fluxes in adjacent regions of the same latitude, which are attributed to large cloud amounts (of about 80\%). Also, note the relatively small DSR values over south-eastern Asia in July $\left(\approx 150 \mathrm{Wm}^{-2}\right)$, where large cloud cover $(\approx 80 \%)$ exists, associated with monsoons. Apart from oceanic areas, there are some extended continental regions with large DSR values, such as the United States, South Europe, North Africa and middle-East in April and 


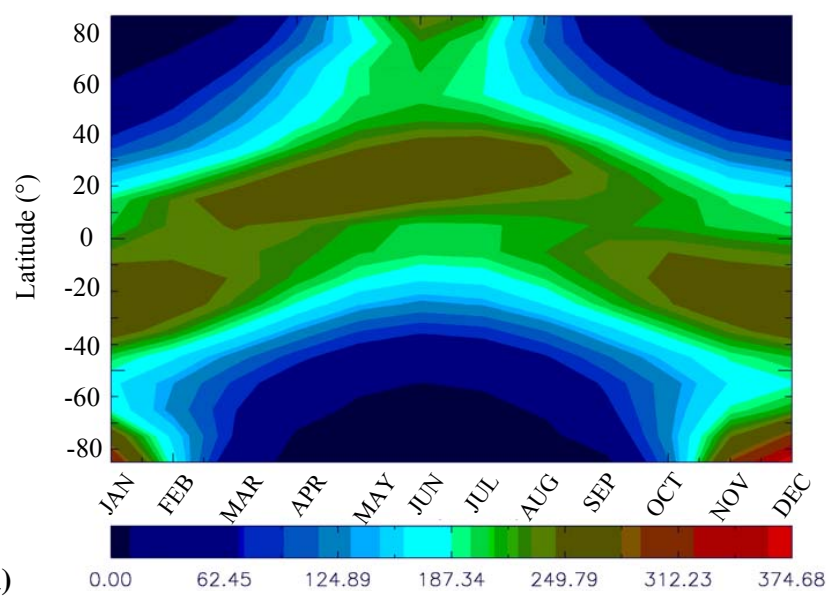

(a)

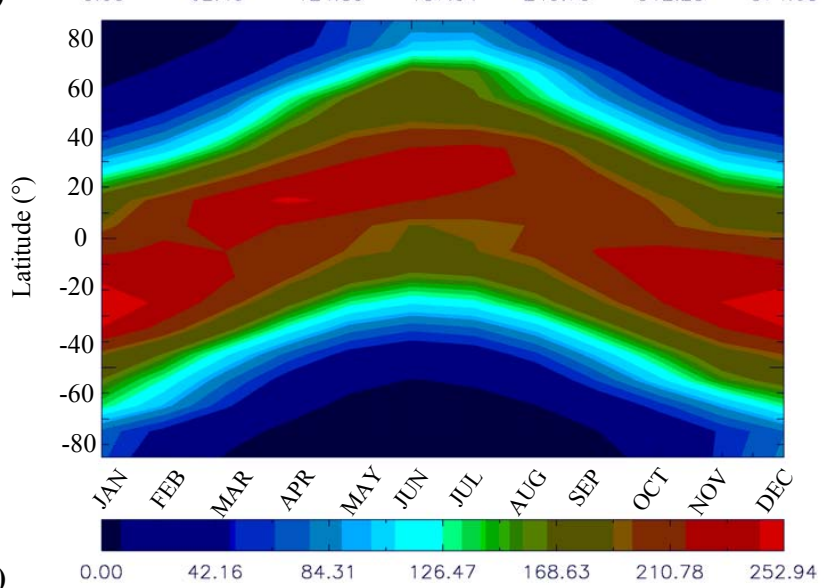

Fig. 3. Seasonal and latitudinal variation of 17-year (19842000) averages of monthly mean (a) downward shortwave radiation (DSR) at the Earth's surface and (b) net downward shortwave radiation (Net DSR) at the Earth's surface. Monthly mean quantities over a $2.5^{\circ} \times 2.5^{\circ}$ geographical grid are plotted.

July, or South America, South Africa and Australia in January and October. In general, the distribution of DSR has similar patterns with the outgoing SW radiation (OSR) at TOA (see Hatzianastassiou et al., 2004a), but with inversed minimum/maximum values.

The net DSR fluxes, given in Figs. 2a-d, are similar to the DSR fluxes. Over oceanic areas, with a small albedo, the differences are quite small, while the most important differences are found over the highly reflecting surfaces, such as deserts or snow- and ice-covered polar areas, having surface albedo values reaching 40 and $95 \%$, respectively, leading thus to small net DSR values $\left(<100 \mathrm{Wm}^{-2}\right)$ over Antarctica in January and the Arctic in July. This is clearly illustrated by a comparison between the north African desert and the adjacent Mediterranean Sea for July (Fig. 2c), which shows differences of about $125-150 \mathrm{Wm}^{-2}$, while there are no significant differences in DSR fluxes (Fig. 1c).
Latitude zonal averages, over the 17-year period, of monthly mean DSR and net DSR fluxes (Figs. 3a, b), show that DSR fluxes vary from zero to $375 \mathrm{Wm}^{-2}$, having maxima over sub-tropical and polar areas of both hemispheres in summer, of about 310 and $370 \mathrm{Wm}^{-2}$, respectively. The maximum values at the South Pole are slightly larger than those of the North Pole, due to the slightly smaller Earth-Sun distance, smaller cloudiness and drier atmosphere. Small seasonal variations exist in the tropics, where weak seasonal variation in solar declination and cloudiness occur. The seasonal variability of DSR increases towards the poles, where it can be up to $375 \mathrm{Wm}^{-2}$. Large DSR values are found in northern hemispherical areas extending from the equator to the North Pole in July, whilst in the southern hemisphere in January, there are relatively smaller DSR fluxes of about $150 \mathrm{Wm}^{-2}$ from $50^{\circ} \mathrm{S}$ to $70^{\circ} \mathrm{S}$, due to large cloudiness along the storm-track zone of South Hemisphere. In both hemispheres, the maximum of DSR values occur in sub-tropical areas (between 10 and $35^{\circ}$ of latitude) rather than in the tropics, apart from the poles. This is due to the fact that total cloudiness has minimum values (of about $50 \%$ ) over the above sub-tropical areas, and not along the equator, where the ITCZ involves total cloud cover values of about $60-70 \%$, according to the ISCCP-D2 data. Our computed zonally averaged DSR values agree with the corresponding 8-year averages given by Gupta et al. (1999), but they are smaller in the polar areas by $30-80 \mathrm{Wm}^{-2}$. In the tropics, $\left(20^{\circ} \mathrm{S}-20^{\circ} \mathrm{N}\right)$, maximum DSR values occur during spring and autumn, and not in summer as in sub-tropical, mid-latitude and polar areas. This behaviour, which has been also reported by Darnell et al. (1992) and Hatzianastassiou and Vardavas (1999), is attributed to maximum values in the incoming solar radiation at TOA during these seasons over the tropics, as well as to relevant features in the annual cycle of cloudiness and total precipitable water. Our maximum DSR and net DSR values in tropical and sub-tropical areas $\left(20^{\circ} \mathrm{S}-20^{\circ} \mathrm{N}\right)$ are slightly larger (by $\approx 10 \mathrm{Wm}^{-2}$ ) than those given by Hatzianastassiou and Vardavas (1999) and even larger than those of Vardavas and Koutoulaki (1995), while over Antarctica they are smaller than those given by Hatzianastassiou and Vardavas (2001) by $20-30 \mathrm{Wm}^{-2}$. The zonally averaged values presented here, however, are more reliable, since the earlier ones were computed using zonal averages of model input data to produce zonal mean fluxes, rather than grid cell-level input data. The net DSR fluxes (Fig. 3b) are quite similar to the DSR ones, but there are also some differences. Thus, the polar areas do not show maxima in net DSR fluxes, while there is a significant inter-hemispherical contrast in terms of the magnitude of summer sub-tropical maximum net DSR values, due to the smaller surface albedo of the South Hemisphere (smaller land-to-sea ratio). 


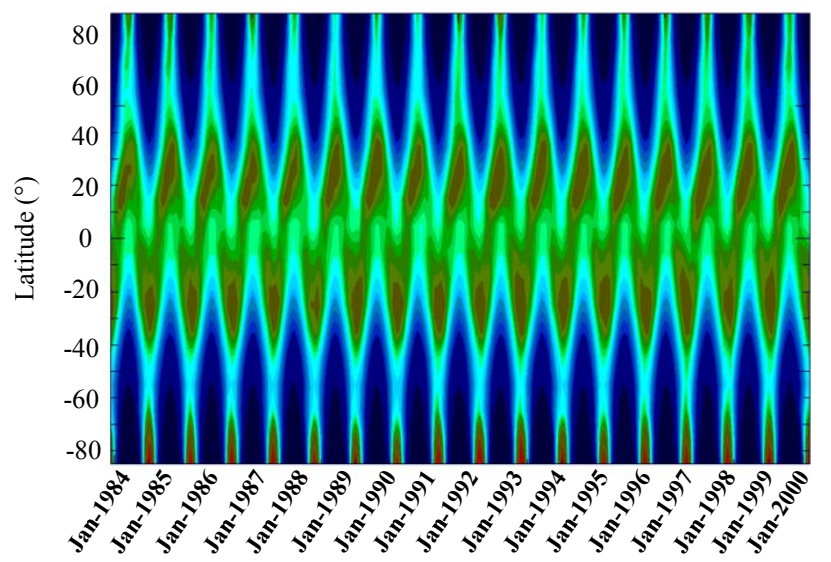

(a)
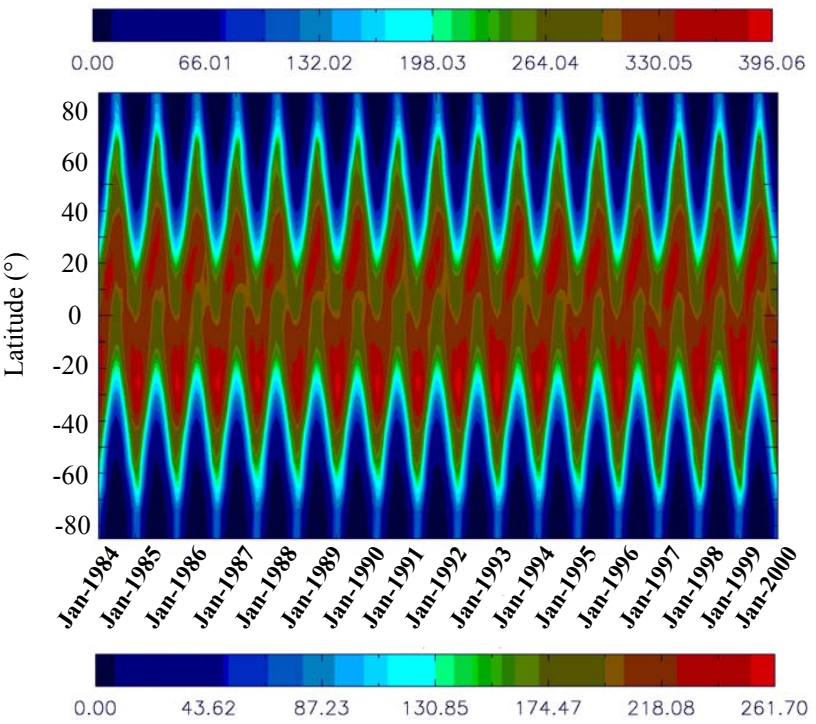

Fig. 4. Time-series of 10-degree latitude-zonal averages of monthly mean (a) downward shortwave radiation (DSR) at the Earth's surface and (b) net downward shortwave radiation (Net DSR) at the Earth's surface, for the period January 1984 - December 2000. Monthly mean quantities over a $2.5^{\circ} \times 2.5^{\circ}$ geographical grid are used.

\subsection{Time series}

The time series of global zonally averaged monthly mean DSR and net DSR fluxes over the entire 204-month period 1984-2000 indicate that the patterns shown in Fig. 3 are repeated over the 17-year period (Fig. 4). Thus, maximum DSR values of about $260-280 \mathrm{Wm}^{-2}$ occur over sub-tropical regions $\left(10^{\circ}-40^{\circ} \mathrm{N}\right.$ and $\left.\mathrm{S}\right)$ during local summer, whereas maximum values are also found in polar areas during summer, which are slightly larger in the southern than northern pole. Local minimum values of about $200 \mathrm{Wm}^{-2}$ are found in equatorial areas, induced by the ITCZ cloudiness, as well as over both hemispherical middle-to-high latitudes (around $60^{\circ} \mathrm{N}$ and $\mathrm{S}$ ), due to the large stratiform cloud amounts over

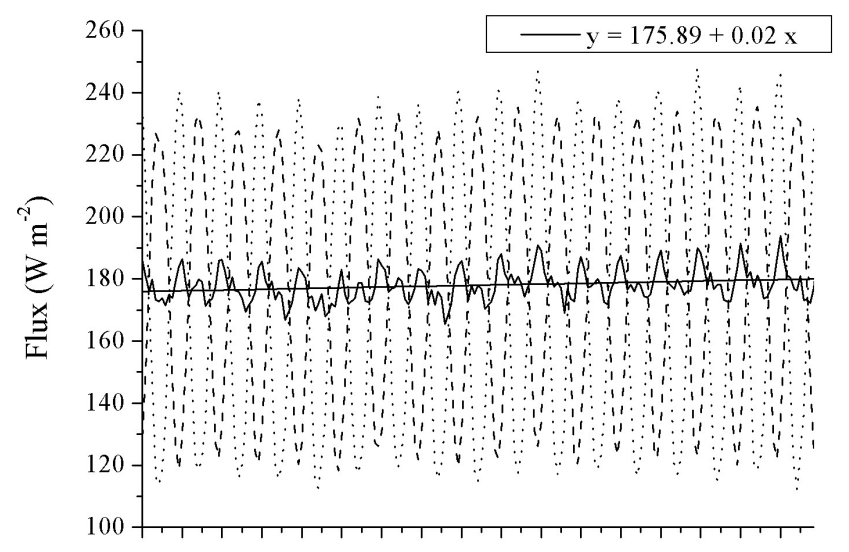

(a)
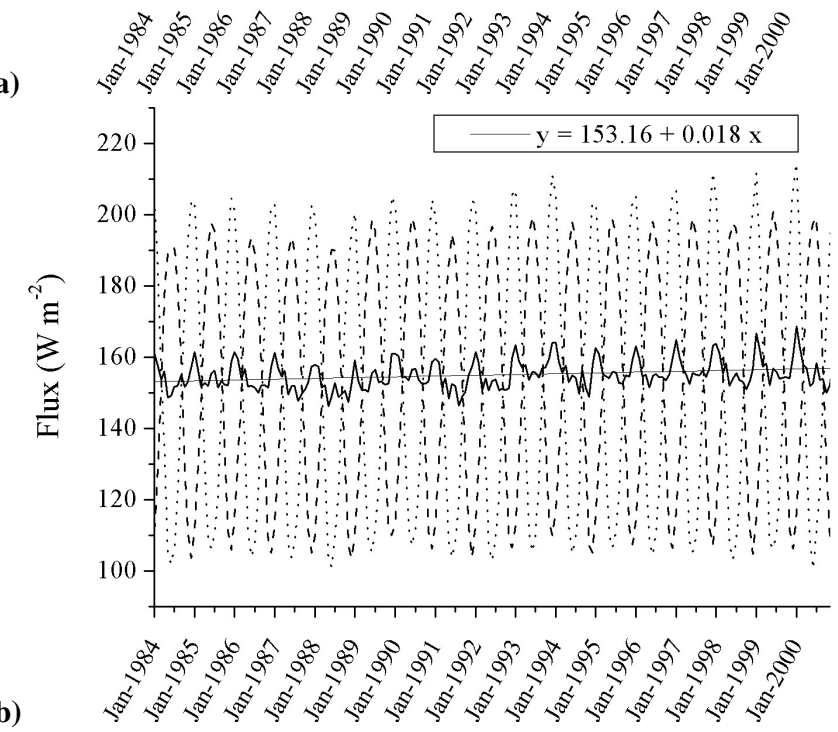

Fig. 5. Time series of monthly average: (a) downward shortwave radiation (DSR) at the Earth's surface (in $\mathrm{Wm}^{-2}$ ) and (b) net downward (or absorbed) shortwave radiation (Net DSR) at the Earth's surface (in Wm ${ }^{-2}$ ), for the 17-year (1984-2000) period for the Globe (solid lines), Northern Hemisphere (dashed lines), and Southern Hemisphere (dotted lines). The linear regression for the time series of the Globe is also shown.

the oceans at these latitudes. The features of net DSR are very similar to those of DSR, except in polar areas, where the net DSR drops down to values of $<100 \mathrm{Wm}^{-2}$. Although there are some inter-annual trends in the surface $\mathrm{SW}$ radiation fluxes, these cannot be clearly seen in plots such as those in Figs. 4a, b, because of the extended scale of values.

The time-series of the mean monthly hemispheric and global average components of the surface SRB, over the period from 1984 to 2000, reveal a strong seasonal cycle for the hemispheric averages of DSR (Fig. 5a). The South Hemisphere has slightly larger amplitude $\left(\approx 125 \mathrm{Wm}^{-2}\right)$ than the North one $\left(\approx 110 \mathrm{Wm}^{-2}\right)$. This is due to the fact that the seasonal cycle of the net incoming SW radiation at TOA is 
larger in the South Hemisphere $\left(\approx 300 \mathrm{Wm}^{-2}\right)$ than in the North one $\left(\approx 250 \mathrm{Wm}^{-2}\right)$. Another reason is that, as shown by our analysis using both NCEP/NCAR and ECMWF data, the total precipitable water of the Northern Hemisphere shows a stronger seasonal cycle than that of the Southern Hemisphere, with very large values (up to $\approx 3.2 \mathrm{~g} \mathrm{~cm}^{-2}$ ) in July, against values of about $2.8 \mathrm{~g} \mathrm{~cm}^{-2}$ in the South Hemisphere, as also reported by Wittmeyer and Vonder Haar (1994). Therefore, the summer-maximum of DSR in the South Hemisphere reaches about $240 \mathrm{Wm}^{-2}$, against 230 $\mathrm{Wm}^{-2}$ in the North one. The hemispherical DSR averages balance each other to produce a monthly mean global average DSR with a small seasonal variability $\left(\approx 10-20 \mathrm{Wm}^{-2}\right)$, with primary and secondary maxima and minima. The applied linear regression to the mean global DSR 17-year timeseries, shows an increasing trend in DSR, equal to $4.1 \mathrm{Wm}^{-2}$ over the time period 1984-2000, which is equivalent to a decadal increasing trend of $2.4 \mathrm{Wm}^{-2}$. This increasing trend in DSR is associated with a 17-year decreasing trend in the reflected outgoing SW radiation (OSR) at TOA, equal to $3.2 \mathrm{Wm}^{-2}$, as shown by Hatzianastassiou et al. (2004a). Note that Pinker et al. (2005), using a model with satellite records, estimated a global increase in DSR from 1983 to 2001 at a rate of $1.6 \mathrm{Wm}^{-2}$ per decade, slightly smaller than ours. Our analysis has shown that the trends in both DSR and OSR are statistically significant with a confidence level of $99 \%$. These trends are not attributed to the incoming SW radiation at TOA, since the latter shows an insignificant trend of $0.1 \mathrm{Wm}^{-2}$, but they are attributed to internal physical processes of the Earth-atmosphere system. Apart from DSR, the net DSR flux has also increased by $3.7 \mathrm{Wm}^{-2}$ over the 17 year period from 1984 to 2000 (or by $2.2 \mathrm{Wm}^{-2}$ on a decadal scale). Note that there is uncertainty in the computed trends in DSR and net DSR, associated with corresponding uncertainties in model input data, especially of clouds. However, based on the reported uncertainties of the ISCCP-D2 data (see Rossow and Schiffer, 1999), and the model sensitivity tests (see, Sect. 5, Table 3) in terms of DSR and net DSR fluxes, the computed trends are larger than the uncertainties induced by the model input data.

We have performed an analysis that shows that the increasing trend in global mean DSR arises, to a large extent, in tropical and sub-tropical areas. Therefore, our study indicates that the change in tropical SW radiation budget at TOA (increasing planetary heating), indicated by both satellite observations (Wielicki et al., 2002) and model computations (Hatzianastassiou et al., 2004a; Fotiadi et al., 2005) is associated with a significant increasing surface solar radiative heating, involving enhancements in both downward and absorbed solar radiation at the Earth's surface, especially in low latitudes. It should be noted that since the long-term increase in net DSR $\left(3.7 \mathrm{Wm}^{-2}\right)$ exceeds the corresponding long-term decrease in OSR $\left(3.2 \mathrm{Wm}^{-2}\right)$, there must be a long-term decrease in SW atmospheric absorption (cooling) by $0.5 \mathrm{Wm}^{-2}$, verified by our study. Overall, our mod- elling study indicates that over the 17-year period from 1984 to 2000, a significant change in the SW radiation budget has taken place, consisting in a planetary solar heating, resulting from a stronger surface solar heating combined with a smaller atmospheric solar cooling. This should have affected the atmospheric dynamics by strengthening the Hadley and Walker circulations (Chen et al., 2002), altering the atmospheric temperature gradient and the formation of clouds and precipitation. Of course, further and more detailed investigations are necessary to draw definite conclusions. For example, the model results, in terms of DSR and net DSR trends, have to be inter-compared with corresponding trends in station measurements, and a relevant work is in preparation. Note that Wild et al. (2005) report a reversal from global dimming (i.e. decreasing DSR) up to 1990, to widespread brightening (i.e. increasing DSR) since the late 1980s, based on available GEBA and BSRN surface observations, in agreement with our results. The reasons of the apparent increasing trend in DSR need to be more thoroughly investigated. A preliminary analysis was performed, in which the correlation coefficients between long-term tendencies in DSR and various physical parameters that determine DSR, were computed. In our model these parameters are: cloud (low, middle and high-level) cover, cloud scattering and absorption optical depths, surface albedo, total precipitable water, total column $\mathrm{O}_{3}$ concentration and incoming SW radiation at TOA. The results of our analysis show that a decrease in cloud cover, especially low-level, is primarily responsible for the increasing trend in DSR. We have also performed another study in which we have computed the contribution of each one of the above relevant physical parameters to the computed trends in DSR and net DSR, as in the works by Hatzidimitriou et al. (2004) and Fotiadi et al. (2005). The results of this analysis show that about $70 \%$ of the total trend in surface solar radiation comes from the low-level clouds. The results of these preliminary analyses are in line with similar studies performed to investigate the physical sources of the corresponding decreasing trend in OSR (Hatzianastassiou et al., 2004a).

The computed anomalies in hemispherical mean DSR fluxes over the 17-year period (1984-2000), vary from -9 to $9 \mathrm{Wm}^{-2}$ (Fig. 6a), while the global mean DSR anomaly has variations of up to $6 \mathrm{Wm}^{-2}$, about the 17 -year mean value. Large negative anomalies, i.e. decreased SW radiation reaching the Earth's surface, are found for the period 1991-1993, which can be attributed to the Mount Pinatubo eruption in June 1991, and to the 1991/1992 El Niño event. During the same period, the outgoing SW radiation has drastically increased by about $4 \mathrm{Wm}^{-2}$ (see Hatzianastassiou et al., 2004a). The induced rapid decrease in DSR is followed by a recovery period, with positive DSR anomalies through 1994. There are also other interesting features corresponding to climatic events, such as El Niño and La Niña, associated with negative and positive DSR anomalies, respectively. For example, negative DSR anomalies as large as $6 \mathrm{Wm}^{-2}$ occur 
around late 1988 and early 1989 following the 1986/1987 El Niño event (Fig. 6a). Our analysis has shown that these large negative anomalies are mostly associated with high values of ISCCP cloud optical thickness, especially of lowand mid-level clouds. The large negative DSR anomalies of about $-5 \mathrm{Wm}^{-2}$ during 1984 can be attributed to the influence of the El Chichon eruption that took place in 1983. Also, note that in 1998 the DSR anomalies pass from large positive values (of about $4 \mathrm{Wm}^{-2}$ ) to negative ones (equal to $-2 \mathrm{Wm}^{-2}$ ), which can be attributed to the $1997 / 1998 \mathrm{El}$ Niño event. Nevertheless, this strong El Niño event cannot be seen clearly in Fig. 6 since it refers to global mean anomalies, while it is apparent in zonal mean DSR anomalies for the zone $0^{\circ}-10^{\circ} \mathrm{S}$ (not shown here). Also, note that in late 2000 there is a strong drop in DSR anomalies, down to values of -2 to $-3 \mathrm{Wm}^{-2}$, related to the 2001-2003 El Niño, outside our study period. The 4th order polynomial fit to 17 -year time-series of global averages of DSR anomalies shows significant positive DSR anomalies (increasing DSR) in the period starting from year 1992 (Fig. 6). On the contrary, in the period 1984-1992, negative DSR anomalies mostly occur, indicating a decreasing DSR flux at the Earth's surface. This is in agreement with most measurements and modelling studies, reporting a decreasing trend in DSR during the period between 1960 and 1990 (e.g. Gilgen et al., 1998; Stanhill and Cohen, 2001; Liepert, 2002; Wild et al., 2004). Our model results, however, show that the situation has changed after the early 1990s, since the surface solar radiation is found to have increased, due to a decrease in cloudiness, especially lowlevel, primarily in tropical and sub-tropical regions. Thus, it seems that during the last decade of the 20th century, the effect of clouds has dominated any other effect. This is expected, given that surface solar radiation is more sensitive to clouds rather than other physical parameters, within the range of their natural variability (cf. Sect. 5).

\subsection{Mean annual, hemispherical, and global surface SW ra-} diation budget components

Monthly mean 10-degree latitude zonal fluxes were computed by averaging first along $2.5^{\circ}$-width longitudinal circles, then along latitude, by considering the fraction of surface area contained in each 2.5-degree zone. Subsequently, annual mean quantities were computed by summing the corresponding monthly means for each 10-degree latitudinal zone over the 12 months of the year. The latitudinal variation of mean annual DSR flux has maximum values of about $230 \mathrm{Wm}^{-2}$ in sub-tropical areas, while it drops rapidly to about $80 \mathrm{Wm}^{-2}$ towards the poles (Fig. 7a). There is a local minimum in mean annual DSR in the equator (equal to about $220 \mathrm{Wm}^{-2}$ ), which is caused by clouds associated with the ITCZ. There is also a local maximum of $230 \mathrm{Wm}^{-2}$ in DSR around $15^{\circ} \mathrm{N}$, in agreement with previous studies (Liou, 1992; Hatzianastassiou and Vardavas, 1999) while Darnell et al. (1992) reported a similar local maximum, but
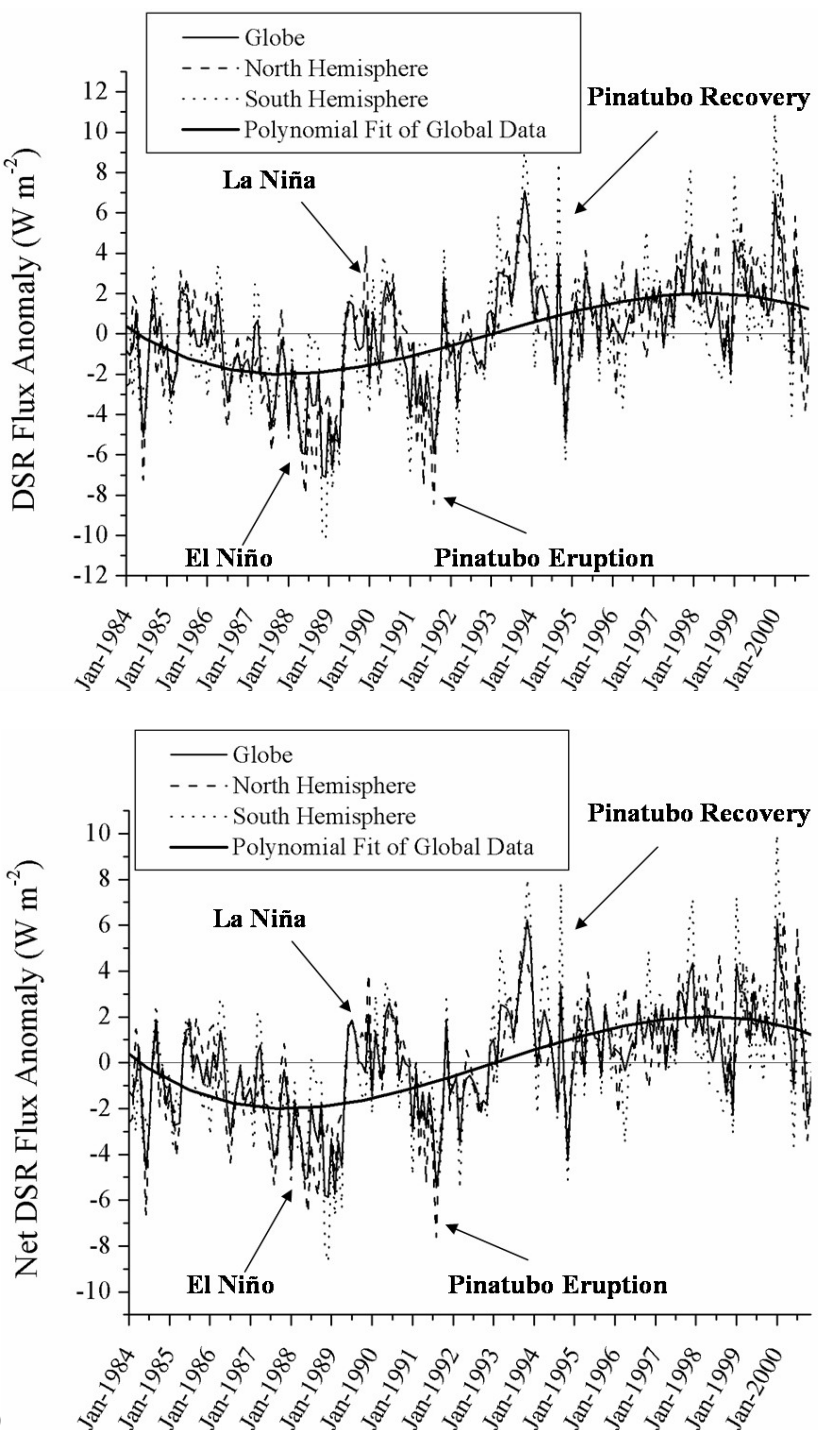

Fig. 6. Time-series of global and hemispherical averages of (a) downward shortwave radiation (DSR) flux anomalies (in $\mathrm{Wm}^{-2}$ ) and (b) net downward shortwave radiation (DSR) flux anomalies (in $\mathrm{Wm}^{-2}$ ) over the period 1984-2000 for the Globe (solid lines), Northern Hemisphere (dashed lines), and Southern Hemisphere (dotted lines). The 4th-order polynomial fit of the global data is also shown.

shifted poleward by $10^{\circ}$ latitude. Note that in the South Hemisphere, there are local minimum and maximum DSR values around $60^{\circ} \mathrm{S}$ and at the south pole, respectively, while in the North Hemisphere there is a continuous equator-topole decrease in DSR. The local minimum in DSR around $60^{\circ} \mathrm{S}$, is caused by the persistent and extended cloudiness occurring over the oceanic zone of South Hemisphere, and underlines the very important role of clouds, apart from that of solar declination, in determining the DSR fluxes. The net DSR flux decreases from about $210 \mathrm{Wm}^{-2}$ in the tropics to $20-30 \mathrm{Wm}^{-2}$ in the polar regions (Fig. 7b). It is very similar 

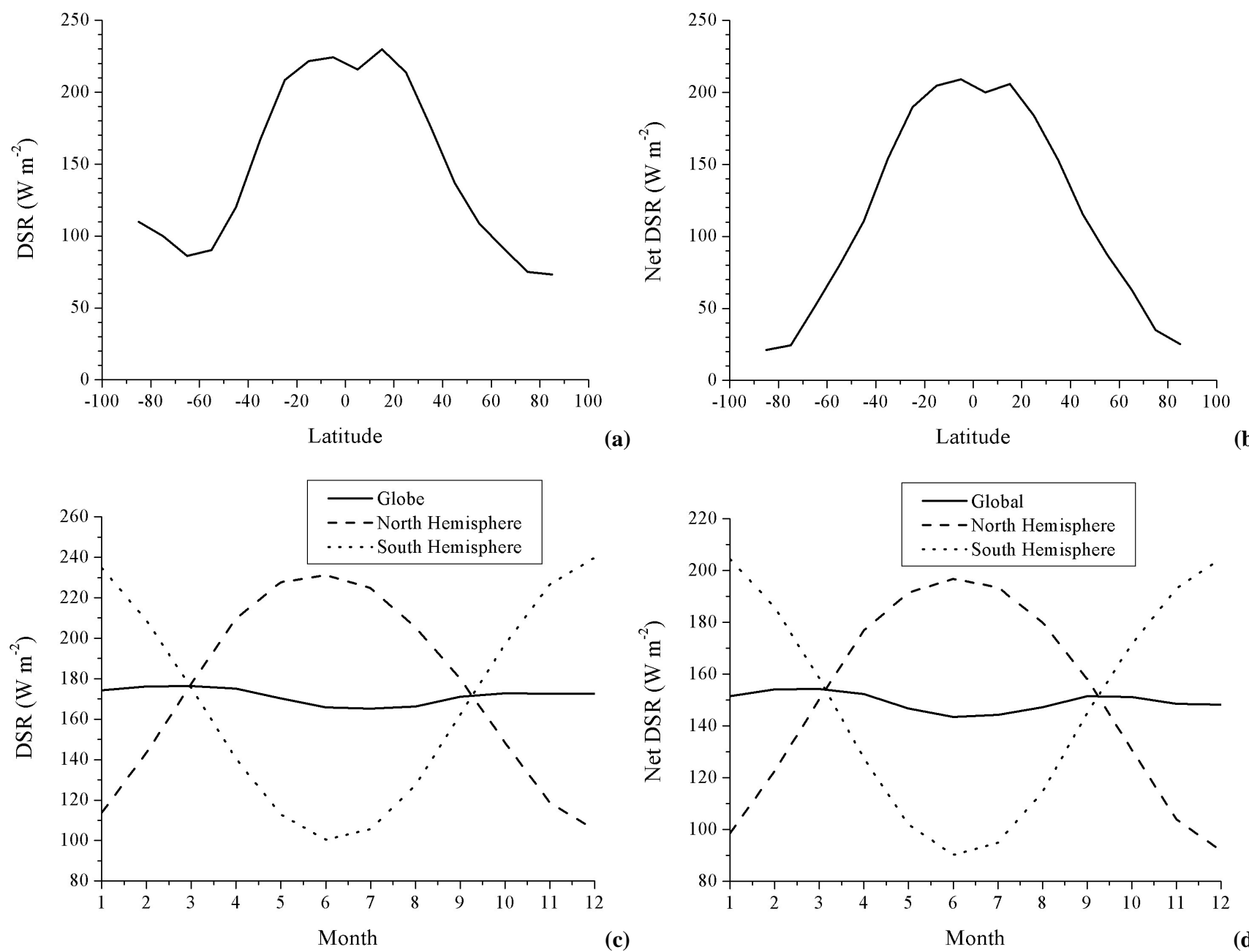

(b)

Fig. 7. Latitudinal variation of model computed: (a) mean annual downward shortwave radiation (DSR in Wm ${ }^{-2}$ ) at the Earth's surface, and (b) mean annual net downward (or absorbed) shortwave radiation (Net DSR in $\mathrm{Wm}^{-2}$ ) at the Earth's surface, averaged over the period January 1984 through December 2000. Also shown is the seasonal variation of hemispherical and global averages of model computed: (c) downward shortwave radiation (DSR in $\mathrm{Wm}^{-2}$ ) at the Earth's surface, and (d) net downward (or absorbed) shortwave radiation (Net DSR in $\mathrm{Wm}^{-2}$ ) at the Earth's surface, averaged over the period January 1984 through December 2000.

to DSR, except for the polar areas, but it has differences as well. Thus, the local minimum in DSR near $60^{\circ} \mathrm{S}$, does not exist in the mean annual net DSR flux, since it is smoothed out by the much larger absorption of DSR by the Antarctic ocean than the adjacent Antarctic continent. Note that in contrast to larger DSR fluxes over Antarctica than the Arctic (Fig. 7a), there are slightly smaller net DSR fluxes, due to Antarctica's larger surface albedo. Our values in the tropics are smaller by $5-10 \mathrm{Wm}^{-2}$ than those given by Hatzianastassiou and Vardavas (1999), in better agreement with GEBA and BSRN surface observations. Also, our net DSR values are found to be at the lower end of the range of values given by Li et al. (1997), based on various observational and modelling estimates, in both tropical and polar areas, in better agreement with surface observations, especially in tropical areas.
The mean hemispherical DSR fluxes have opposite seasonalities, varying within the range $110-230 \mathrm{Wm}^{-2}$, resulting thus in a mean global DSR flux ranging from 165 to $176 \mathrm{Wm}^{-2}$ throughout the year (Fig. 7c). The corresponding seasonal variation in global mean net DSR flux is equal to $8 \mathrm{Wm}^{-2}$ (Fig. $7 \mathrm{~d}$ ). There is a smaller seasonal variation in net DSR than DSR for both hemispheres and the globe, which is attributed to the effect of surface albedo. Nevertheless, for both DSR and net DSR, the seasonal variability is slightly larger in the southern than in the northern hemisphere. The northern hemispherical mean net DSR fluxes are smaller than the corresponding values given by Hatzianastassiou and Vardavas (1999) by 10 and $15 \mathrm{Wm}^{-2}$, in terms of their winter minimum and summer maximum values. 
The mean annual hemispherical and global average values over the 17-year period from 1984 to 2000, for the downward and net downward (i.e. absorbed) SW radiation at surface, along with corresponding values for the 4 mid-seasonal months of the year, are given in Table 1, while in Table 2, our computed DSR and net DSR values are also intercompared with other published values. Note that very few other studies give both SRB components for the two hemispheres and the globe. On a 17-year basis, the Earth's surface is found to receive $171.6 \mathrm{Wm}^{-2}$ and to absorb $149.4 \mathrm{Wm}^{-2}$, resulting in a long-term surface albedo equal to $12.9 \%$. The interhemispherical differences are equal to $4.6 \mathrm{Wm}^{-2}$ for DSR and only $0.3 \mathrm{Wm}^{-2}$ for net DSR, implying slightly larger northern than southern hemispherical surface solar radiative fluxes. Overall, according to our 17-year model results using ISCCP-D2 data, on a mean annual basis and at global scale, the Earth receives $50.2 \%$, while it absorbs $43.7 \%$ of the incoming SW radiation entering the Earth-atmosphere system. Our model-computed values are very close to those given by surface observations (GEBA), with differences equal to 2.6 and $1.6 \mathrm{Wm}^{-2}$ for DSR and net DSR, respectively, while they are significantly smaller than most estimates from other physical deterministic models, GCMs and climatic models, as well as from reanalysis products, by up to $30 \mathrm{Wm}^{-2}$. In contrast, our model results seem to be close to those of the ECHAM model and the recently published ISCCP-FD fluxes (Zhang et al., 2004), as well as those of ECMWFERA. Note that in previous SRB studies, a significant overestimation of net DSR flux has been reported, with respect to the surface-based estimate given by Ohmura and Gilgen (1993), involving an uncertainty in the knowledge of SRB (Li et al., 1997; Kiehl and Trenberth, 1997) of about 20$25 \mathrm{Wm}^{-2}$. This overestimation has been associated with extra atmospheric solar absorption (by clouds or aerosols) as indicated by observational studies (Cess et al., 1995; Ramanathan et al., 1995; Pilewski and Valero, 1995), but also verified by modelling studies (Garratt et al., 1998; Wild et al., 1998; Hinkelman et al., 1999). On the other hand, it has been argued that the surface-based estimate by Ohmura and Gilgen (1993) was probably too low, since it was derived by measurements taken at a limited number of stations, usually located over land areas (Kiehl and Trenberth, 1997) and especially populated ones (Li et al., 1997). Since then, the number of stations involved in GEBA and BSRN networks has increased, and their spatial coverage expanded to cover remote areas, such as Greenland and Antarctica. Recently, the "best" surface-based estimate of surface solar absorption (net DSR) has been revised to $151 \mathrm{Wm}^{-2}$ for net DSR, close to our model computed value of $149.4 \mathrm{Wm}^{-2}$.

\section{Sensitivity of surface SW radiation budget}

The assessment and quantification of the role of various physical key parameters that determine the DSR and net DSR
Table 1. Model computed mean annual hemispherical (NH is Northern Hemisphere, SH is Southern Hemisphere) and global averages of downward shortwave radiation (DSR) and net downward shortwave radiation (net DSR) at the Earth's surface for January, April, July, October, and the whole year, for the 17-year (19842000) period. The radiative fluxes are expressed in $\mathrm{Wm}^{-2}$. Numbers in parenthesis are standard deviations and represent interannual variabilities of the means.

\begin{tabular}{|c|c|c|c|}
\hline & $\mathrm{NH}$ & $\mathrm{SH}$ & Global \\
\hline \multicolumn{4}{|c|}{ Downward Shortwave Radiation } \\
\hline January & $113.8(9.8)$ & $234.8(20.7)$ & $174.3(15.3)$ \\
\hline April & $209.8(16.5)$ & $140.4(11.5)$ & $175.1(14.0)$ \\
\hline July & $224.8(17.2)$ & $105.6(7.7)$ & $165.2(12.5)$ \\
\hline October & $148.6(12.0)$ & $197.0(16.6)$ & $172.8(14.3)$ \\
\hline Annual & $173.9(14.0)$ & $169.3(14.3)$ & $171.6(14.1)$ \\
\hline \multicolumn{4}{|c|}{ Net Downward Shortwave Radiation } \\
\hline January & $98.6(2.7)$ & $204.5(6.5)$ & $151.6(4.6)$ \\
\hline April & $177.0(4.6)$ & $127.5(3.4)$ & $152.2(4.0)$ \\
\hline July & $193.6(5.1)$ & $94.9(2.1)$ & $144.2(3.6)$ \\
\hline October & $130.9(3.5)$ & $171.6(4.3)$ & $151.2(3.9)$ \\
\hline Annual & $149.6(3.9)$ & $149.3(4.0)$ & $149.4(4.0)$ \\
\hline
\end{tabular}

fluxes at surface is very important for SW radiation budget studies. To this aim, a series of sensitivity tests were performed with our model. In each test, the relevant parameter, $V$, was modified by a certain amount, $\Delta V$, i.e. by $10 \%$ in most cases, in relative percentage terms, and the modifications of the downward SW radiation at surface, $\Delta$ (DSR), and of the net DSR flux at surface, $\Delta$ (NDSR), with respect to the defined reference cases, were computed and subsequently expressed either in absolute terms (in $\mathrm{Wm}^{-2}$ ) or in relative percentage values. The results given in Table 3 provide values in absolute terms. The year 1988 was chosen to represent the reference case. The tests were performed on a monthly basis and at the grid cell level, but results are given here in terms of globally and annually averaged $\Delta$ (DSR) and $\Delta$ (NDSR) absolute values. Our model sensitivities are valuable for assessing possible sources for discrepancies between modelcomputed and surface-measured DSR and net DSR fluxes, as well as for evaluating the uncertainties in the computed DSR and net DSR fluxes due to uncertainties in model input data. The results of our model sensitivity tests indicate that, on a mean annual and global basis, DSR is found to be primarily sensitive to cloud parameters, namely the cloud cover, cloud optical depth (especially the scattering one), cloud asymmetry parameter, as well as to total precipitable water. Increasing $A_{c}$ by $10 \%$, separately for low, middle, or high-level clouds, resulted in a decrease of DSR by up to $3.2 \mathrm{Wm}^{-2}$ (or about $2 \%$ ). The DSR fluxes were found to be more sensitive to low rather than to middle or high-level clouds. This is also valid for the sensitivity of DSR to $\tau_{c}^{s}$; thus, increasing $\tau_{c}^{s}$ by $10 \%$ reduced DSR by up to $1.2 \mathrm{Wm}^{-2}$. Modifying 
Table 2. Model mean annual hemispherical and global averages of downward shortwave radiation at the Earth's surface (DSR), and net downward shortwave radiation (i.e. absorbed) at the Earth's surface (Net DSR), as computed in this study, compared with values from others. NH is Northern Hemisphere, $\mathrm{SH}$ is Southern Hemisphere. The radiative fluxes are expressed in $\mathrm{Wm}^{-2}$.

\begin{tabular}{|c|c|c|c|c|c|c|}
\hline \multirow{2}{*}{ Study } & \multicolumn{3}{|c|}{ DSR } & \multicolumn{3}{|c|}{ Net DSR } \\
\hline & $\mathrm{NH}$ & SH & Globe & $\mathrm{NH}$ & SH & Globe \\
\hline Present Study (1984-2000) & 173.9 & 169.3 & 171.6 & 149.6 & 149.3 & 149.4 \\
\hline Zhang et al. (2004) & & & 165.2 & & & \\
\hline Liou (2002) & & & 189.0 & & & 161.0 \\
\hline Hatzianastassiou and Vardavas (2001) & & 174.0 & & & 160.0 & \\
\hline Hatzianastassiou and Vardavas (1999) & 177.9 & & & 156.6 & & \\
\hline Global Energy Balance Archive (GEBA) & & & 169.0 & & & 151.0 \\
\hline Gupta et al. (1999) (8-yr 1983-1991) & 186.7 & 182.6 & 184.7 & 160.2 & 161.5 & 160.9 \\
\hline CSU/GCM (Gupta et al., 1999) & 202.3 & 200.5 & 201.4 & 177.4 & 178.9 & 178.2 \\
\hline NCAR/GCM2 (Gupta et al., 1999) & & & & 179.1 & 181.5 & 180.3 \\
\hline NCAR/GCM3 (Gupta et al., 1999) & 194.4 & 194.4 & 194.4 & 169.0 & 173.4 & 171.2 \\
\hline Wild and Ohmura (1999 - ARPEGE) & & & & & & 174.0 \\
\hline Wild et al. (1999 - HadAM2b) & & & & & & 175.0 \\
\hline Wild (2004 - ECHAM5) & & & 180.0 & & & 156.0 \\
\hline Wild et al. (1998a - ECHAM4) & & & 170.0 & & & 147.0 \\
\hline Wild et al. (1998a - ECHAM3) & & & 189.0 & & & 164.0 \\
\hline GCM studies (Wild et al., 1998a) & & & & & & $164.0-182.0$ \\
\hline Garratt et al. (1998) & & & 190.0-201 & & & $160.0-174.0$ \\
\hline Kiehl and Trenberth (1997) & & & & & & 168.0 \\
\hline Modelling studies (Li et al., 1997) & & & & & & $157.0-190.6$ \\
\hline Del Genio et al. (1996) & & & & 172.0 & & \\
\hline Fowler and Randall (1996) & & & & & & 172.0 \\
\hline Li et al. (1995) & & & & & & 157.0 \\
\hline Rossow and Zhang (1995) & & & 193.4 & & & 165.1 \\
\hline Vardavas and Koutoulaki (1995) & & & & 156.5 & & \\
\hline Hartmann (1994) & & & & & & 171.0 \\
\hline Li and Leighton (1993) & & & & 155.0 & 159.0 & 157.0 \\
\hline Ohmura and Gilgen (1993) & & & & & & 142.0 \\
\hline Darnell et al. (1992) & & & 173.0 & & & 151.0 \\
\hline Peixoto and Oort (1992) & & & & & & 171.0 \\
\hline Rossow and Lacis (1990) & & & & 169.0 & & \\
\hline Rossow and Lacis (1990) GISS GCM & & & & 158.0 & & \\
\hline Ramanathan (1987) & & & & & & 169.0 \\
\hline NCEP Reanalysis (1982-1994) & & & 207.0 & & & 162.0 \\
\hline ECMWF Reanalysis (1985-1993) & & & 180.0 & & & 152.0 \\
\hline NASA Reanalysis (1981-1992) & & & 219.0 & & & 191.0 \\
\hline NASA GEWEX Reanalysis (1983-1992) & & & 186.2 & & & 164.6 \\
\hline
\end{tabular}

the cloud asymmetry parameter, $g_{c}$, by $5 \%$ in relative values, modified DSR by as much as $8 \mathrm{Wm}^{-2}$. This shows that the surface solar radiation is very sensitive to $g_{c}$, which justifies the special care that was taken in modelling this cloud parameter in our study. According to our modelling study, changes in the incoming solar radiation at TOA by $1 \%$ (or by about $3.5 \mathrm{Wm}^{-2}$ ) can modify DSR by $1.7 \mathrm{Wm}^{-2}$ at the global scale, which is important in terms of possible climatic change due to solar variability. It is interesting that, based on our model sensitivity study, increasing the total precipitable water by $10 \%$, results in a globally averaged decrease in DSR by about $2 \mathrm{Wm}^{-2}$ (or about $1.1 \%$ ), which can be important in view of the existing differences between available humidity data from different reanalysis products (e.g. NCEP/NCAR or ECMWF). Much larger $\Delta$ (DSR) values are computed on a local scale in our sensitivity tests, as can be seen in Table 3 . The sensitivity $\Delta$ (NDSR) values are slightly smaller than the $\Delta$ (DSR) ones, apart from the case of surface albedo.

In order to investigate the effect of using humidity data from different sources, we have performed another sensitivity study, in which the model was run for the years 1985-1993 by using data either from the NCEP/NCAR or the ECMWF ERA-15 reanalysis projects, and compared the resulting DSR fluxes at grid cell-level (2.5-degree 
Table 3. Global and annual mean differences, $\Delta$ (DSR) and $\Delta$ (NDSR) in $\mathrm{Wm}^{-2}$, in model computed downward $\mathrm{SW}$ radiation at the Earth's surface (DSR), and net downward SW radiation at the Earth's surface (Net DSR or NDSR), induced by variation $(\Delta V$ in relative percentage value, $\%)$ of the variable $V\left(A_{c}\right.$, cloud cover; $\tau_{c}^{s}$, cloud scattering optical depth; $\tau_{c}^{a}$, cloud absorption optical depth; $g_{c}$, cloud asymmetry parameter; $W_{\mathrm{H}_{2} \mathrm{O}}$, total precipitable water; $W_{\mathrm{O}_{3}}$, total ozone column abundance; $W_{\mathrm{CO}_{2}}$, total column carbon dioxide; $R_{g}$, surface albedo; ISR, incoming SW radiation at TOA; AOT, aerosol scattering optical depth; $\omega_{\text {aer }}$, aerosol single scattering albedo; $g_{\text {aer }}$, aerosol asymmetry parameter). In parenthesis, is given the range of variation for $\Delta$ (DSR) and $\Delta$ (NDSR) at grid cell (2.5-degree latitude-longitude) level, for each sensitivity test. Year 1988 is the reference case.

\begin{tabular}{lcrr}
\hline reference & & 174.01 & 151.76 \\
\hline$V$ & $\Delta V$ & $\Delta$ (DSR) & $\Delta$ (NDSR) \\
\hline Low- $A_{c}$ & 10 & $-3.20(-22.05-0.12)$ & $-2.79(-21.06-0.03)$ \\
Middle- $A_{c}$ & 10 & $-2.24(-17.51-0.39)$ & $-1.87(-16.46-0.12)$ \\
High- $A_{c}$ & 10 & $-2.05(-15.30-0.85)$ & $-1.83(-14.6-0.8)$ \\
Low- $\tau_{c}^{s}$ & 10 & $-1.17(-5.92-0)$ & $-1.04(-5.64-0.1)$ \\
Middle- $\tau_{c}^{s}$ & 10 & $-0.81(-5.21-0)$ & $-0.69(-4.9-0.1)$ \\
High- $\tau_{c}^{s}$ & 10 & $-1.07(-5.84-0)$ & $-0.96(-5.53-0.02)$ \\
Low- $\tau_{c}^{a}$ & 10 & $-0.32(-1.64-0)$ & $-0.30(-1.56-0)$ \\
Middle- $\tau_{c}^{a}$ & 10 & $-0.20(-1.52-0)$ & $-0.17(-1.28-0)$ \\
$\mathrm{High}-\tau_{c}^{a}$ & 10 & $-0.25(-1.37-0)$ & $-0.22(-1.11-0)$ \\
$g_{c}$ & 5 & $7.93(0-20.64)$ & $6.98(-0.69-19.66)$ \\
$W_{\mathrm{H}_{2} \mathrm{O}}$ & 10 & $-1.94(-6.65-0.02)$ & $-1.73(-6.34-0.02)$ \\
$W_{\mathrm{O}_{3}}$ & 10 & $-0.72(-3.37-0.01)$ & $-0.61(-1.55-0.01)$ \\
$W_{\mathrm{CO}}$ & 10 & $-0.1(-0.51-0.01)$ & $-0.08(-0.33-0.01)$ \\
$R_{g}$ & 10 & $-1.05(0.02-13.41)$ & $-3.53(-94.52-0)$ \\
$\mathrm{ISR}$ & 1 & $1.74(0-4.63)$ & $1.52(0-3.22)$ \\
$\mathrm{AOT}$ & 10 & $-0.16(-2.62-0.01)$ & $-0.12(-2.03-0.01)$ \\
$\omega_{\text {aer }}$ & 10 & $0.58(0-11.81)$ & $0.44(-0.01-8.0)$ \\
$g_{\text {aer }}$ & 10 & $0.26(-0.02-4.79)$ & $0.21(-0.05-3.72)$ \\
\hline & & &
\end{tabular}

longitude-latitude) and on a monthly mean basis. The results are given in Fig. 8, where one can see that overall, the DSR fluxes are highly correlated $(\mathrm{R}=99.96 \%)$, with a standard deviation of $2.16 \mathrm{Wm}^{-2}$ and a very small bias, equal to $0.07 \mathrm{Wm}^{-2}$, corresponding to only $0.04 \%$ of the mean annual global DSR flux. This verifies that using NCEP/NCAR or ECMWF data in our model, has little impact on the computed DSR fluxes. Using ECMWF data generally leads to larger DSR fluxes than using data from NCEP/NCAR. Nevertheless, our more detailed analysis has shown that somewhat larger differences in DSR are found at the grid cell level, although in the majority of cases they do not exceed $2 \mathrm{Wm}^{-2}$. For specific cases, however, DSR differences reach values of $10 \mathrm{Wm}^{-2}$; this is the case over areas with a significant topography, such as the Tibetan plateau, Greenland, Rocky Mountains or the Andes. Over these areas, the ECMWF specific humidity is lower than that of NCEP/NCAR, by up to $10-20 \mathrm{~g} / \mathrm{Kg}$, leading thus to larger DSR fluxes.

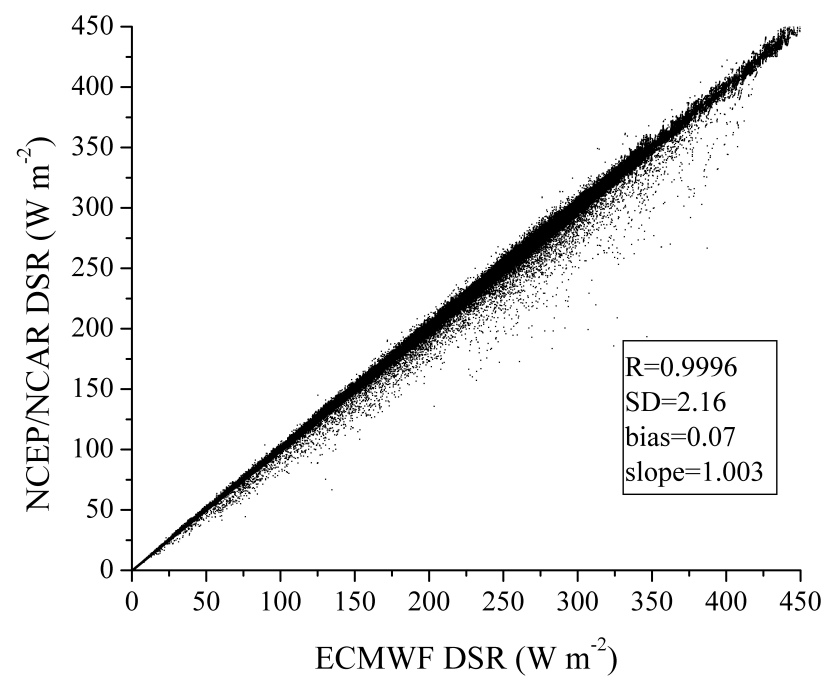

Fig. 8. Scatter plot comparison between model-computed downward shortwave radiation (DSR) at Earth's surface, over the time period 1986-1993, by using model input data for surface and atmospheric properties, taken from the NCEP/NCAR and ECMWF data bases.

\section{Comparisons with surface-site measurements}

The model computed DSR fluxes have been validated through comparison with corresponding extensive measurements from stations. Such high-quality surface-based data were taken from two sources, namely the Baseline Surface Radiation Network (BSRN, Ohmura et al., 1998) and the Global Energy Balance Archive (GEBA, Gilgen and Ohmura, 1999). The BSRN stations have to follow specific observational and calibration procedures, resulting in standardized data of very high accuracy. The temporal resolution of the data is also exceptional, of the order of minutes. All flux data in the BSRN database are quality checked by WCRP. If more than $80 \%$ of the minute values in a specific day pass the quality control, they are subsequently averaged to yield daily values. If this happens for more than 20 days in a month, then monthly values are also computed. We then compare these monthly values with the monthly values calculated by our model. The BSRN network was established in 1992 and the stations from which at least one monthly DSR value in the period 1992-2000 is available, are listed in Table 4 . The comparison of observed versus calculated monthly mean DSR fluxes within the $2.5^{\circ} \times 2.5^{\circ}$ cell containing the BSRN station for all 22 stations, is shown in the scatterplot of Fig. 9a, while the summarised results of model-BSRN comparison, in terms of bias, root mean square error (RMS) and the slope of the least-squares line, for each station, are also listed in Table 4.

The scatterplot shows a bias equal to $-14 \mathrm{Wm}^{-2}$, with a relatively small scatter (RMS equal to $30.6 \mathrm{Wm}^{-2}$ ). A more detailed analysis of the results of model validation against 
Table 4. Baseline Surface Radiation Network (BSRN) stations with measurements of downward SW radiation (DSR) at surface in the period 1992-2000 used for validation of model DSR results. Lat is latitude; Lon is longitude; Elev is elevation (in m); Period is years for which each station gave quality checked DSR monthly fluxes; Bias is the average difference of computed and observed fluxes; RMS is the root mean square error of computed fluxes; Slope is the least-squares line slope and its uncertainty at the $95 \%$ confidence interval and $\mathrm{N}$ is number of mean monthly fluxes used.

\begin{tabular}{lcccccccc}
\hline Station Name & Lat & Lon & Elev. & Period & Bias & RMS & Slope & N \\
\hline Ny Alesund, Norway & 78.9 & 12.0 & 11 & $92-00$ & -13.85 & 24.45 & $0.92 \pm 0.09$ & 37 \\
Barrow, Alaska & 71.3 & -156.6 & 8 & $92-00$ & -14.56 & 34.42 & $0.85 \pm 0.08$ & 72 \\
Toravere, Estonia & 58.4 & 26.8 & 70 & $99-00$ & 3.39 & 7.47 & $0.98 \pm 0.06$ & 11 \\
Lindenberg, Germany & 52.2 & 14.1 & 125 & $94-00$ & -17.27 & 22.71 & $0.86 \pm 0.03$ & 74 \\
Payerne, Switzerland & 46.8 & 6.9 & 491 & $92-97$ & -2.44 & 11.30 & $0.97 \pm 0.04$ & 50 \\
Regina, Canada & 50.2 & -104.3 & 574 & $95-99$ & -19.85 & 24.21 & $1.02 \pm 0.05$ & 57 \\
Chesapeake Light, Virginia & 36.9 & -75.7 & 0 & 2000 & -7.78 & 10.96 & $1.07 \pm 0.19$ & 6 \\
Carpentras, France & 44.0 & 5.0 & 110 & $96-00$ & -9.95 & 11.83 & $0.99 \pm 0.02$ & 44 \\
Boulder, Colorado & 40.0 & -105.0 & 1577 & $92-00$ & -15.28 & 22.01 & $1.12 \pm 0.04$ & 84 \\
Tateno, Japan & 36.0 & 140.1 & 25 & $97-00$ & -6.36 & 18.21 & $1.23 \pm 0.11$ & 39 \\
Bermuda & 32.3 & -64.8 & 8 & $92-00$ & 5.03 & 16.02 & $1.05 \pm 0.05$ & 104 \\
Kwajalein, Marshal Islands & 8.7 & 167.7 & 10 & $92-00$ & -6.75 & 12.02 & $0.83 \pm 0.07$ & 104 \\
Ilorin, Nigeria & 8.5 & 4.6 & 350 & $92-95$ & 29.10 & 36.11 & $1.34 \pm 0.35$ & 26 \\
Nauru Is. & -0.5 & 166.9 & 7 & $98-99$ & -11.74 & 14.01 & $0.89 \pm 0.33$ & 8 \\
Manus Is., Papua New Guinea & -2.1 & 147.4 & 6 & 2000 & 10.47 & 10.47 & - & 1 \\
Alice Springs, Australia & -23.7 & 133.9 & 547 & $95-00$ & -15.86 & 17.61 & $0.97 \pm 0.03$ & 70 \\
Florianopolis, Brazil & -27.5 & -48.5 & 11 & $94-99$ & 2.24 & 13.00 & $0.67 \pm 0.33$ & 14 \\
De Aar, South Africa & -30.7 & 24.0 & 1311 & 2000 & -14.52 & 18.04 & $0.86 \pm 0.16$ & 6 \\
Lauder, New Zealand & -45.0 & 169.7 & 370 & $99-00$ & -44.19 & 50.73 & $0.74 \pm 0.09$ & 17 \\
Georg von Neumayer, Antarctica & -70.6 & -8.2 & 42 & $92-00$ & -45.79 & 58.00 & $0.67 \pm 0.06$ & 31 \\
Syowa, Antarctica & -69.0 & 39.6 & 29 & $94-00$ & -71.91 & 86.49 & $0.60 \pm 0.07$ & 46 \\
South Pole & -90.0 & - & 2841 & $92-00$ & -26.78 & 30.57 & $1.00 \pm 0.04$ & 38 \\
\hline
\end{tabular}

BSRN, shows that the biases do not exceed $10 \mathrm{Wm}^{-2}$ in tropical and mid-latitude areas of both hemispheres, while the corresponding RMS values remain smaller than about $20 \mathrm{Wm}^{-2}$. Despite this quite good model performance, there is some underestimation of DSR fluxes with respect to BSRN in stations situated in southern polar areas $\left(67^{\circ}-90^{\circ} \mathrm{S}\right)$, as can be seen in Table 4. This was also found by comparison against GEBA DSR data (Fig. 9b). Nevertheless, note that similar underestimation features of surface solar radiation fluxes with respect to site measurements in polar areas, have been reported also by others (e.g. Wild et al., 1998a, 2004; Wild and Ohmura, 1999). The largest biases and RMS values are found at the stations of Syowa and Neumayer, along Antarctica's coast. Also, the least square line slope is significantly less than unity in these stations, in contrast to values very close to unity for the rest of stations. However, the South Pole station shows much less underestimation and a least-squares line slope equal to one. This is evidence that the model underestimates DSR in the Antarctic coast not because of model deficiencies related to the polar climate, but more likely because of errors in model input data. Since the detection of clouds is problematic over highly reflecting surfaces, such as the poles, and the good model performance at the South Pole station, it seems that clouds might not be the problem. Given that over Antarctica's coastal areas, the model also underestimates OSR (see Hatzianastassiou et al., 2004a), the situation is rather puzzling, and certainly a more detailed analysis is necessary, including careful check of the site measurements. Apart from a few stations, the model generally underestimates DSR with respect to BSRN, resulting thus in an overall negative bias. Examination of the seasonal behaviour of our model performance against BSRN, shows that generally, zero bias is within the error bars, except for the polar regions during summer, and most of the year in the southern mid-latitude areas.

A similar comparison of measured against model computed DSR fluxes is performed using another DSR database, the Global Energy Balance Archive (GEBA, Gilgen and Ohmura, 1999). The GEBA contains quality checked monthly means of energy fluxes at the Earth's surface from sites all over the world. Data stored in the GEBA database have been extracted from periodicals, monographs, data reports, and unpublished manuscripts. About 700 stations with at least one monthly DSR value in the period 1984-2000 were used in the validation of our model. In Fig. 9b is shown the scatterplot comparison of all monthly measured values against the computed values in the $2.5^{\circ} \times 2.5^{\circ}$ grid cell containing the specific GEBA station. Similarly to the BSRN 
comparison, our model underestimates DSR in the polar areas, but everywhere else the agreement is very good, with an overall bias equal to $-6.5 \mathrm{Wm}^{-2}$ and a RMS value of $23.5 \mathrm{Wm}^{-2}$. The GEBA polar stations show that our model underestimates the DSR, similarly to the BSRN stations, but GEBA, in contrast to BSRN, does not show any evidence of DSR underestimation in the southern mid latitudes. The much smaller number of BSRN measurements (939) than that of GEBA (27858), due to the shorter period covered (1992-2000 against 1984-2000), should be at least partly responsible for the better agreement between model and GEBA than BSRN. But, probably, the most important reason could be the different geographical distribution of stations in the two networks: a significant number of BSRN stations ( 7 out of 22) are located poleward of $50^{\circ} \mathrm{N}$ and S, while GEBA includes a comparatively small fraction of stations (out of total 700) located in sub-polar and polar areas. This is essential, since it is well known that the high-latitude areas are worse sampled by satellites than lower-latitude areas.

\section{Summary and conclusions}

An improved physical deterministic radiative transfer model along with long-term climatological data for various key physical surface and atmospheric parameters have been used to compute the SW surface radiation budget (SRB) for the 17-year period from 1984 to 2000, on a mean monthly basis and $2.5^{\circ}$ by $2.5^{\circ}$ longitude-latitude grid cell resolution at global scale. The data were taken from large data bases such as ISCCP-D2, TOVS, GADS, NCEP/NCAR and ECMWF Global Reanalysis projects. The model results were validated against quality BSRN and GEBA data for the periods 1992-2000 and 1984-2000, respectively, showing good agreement with surface measurements, with an overall negative bias of 14 and $6.5 \mathrm{Wm}^{-2}$, with respect to BSRN and GEBA measurements, respectively. The better agreement with GEBA than BSRN data is probably associated with the larger number of GEBA than BSRN station measurements, and with the different geographical distribution of stations. Namely, the BSRN includes a larger fractional number of stations located in sub-polar and polar areas than GEBA, which are not as well sampled by satellites as areas of lower latitude. The differences between model-computed and surfacemeasured DSR fluxes, are within $10 \mathrm{Wm}^{-2}$ at most stations, i.e. close to the uncertainty of BSRN and GEBA data, except for two stations along Antarctica's coast, where systematically larger differences in DSR fluxes were found. Uncertainties in model input data are assessed to be the most likely source for this model DSR underestimation, whereas similar underestimation features at the same stations have been reported by other modelling studies, suggesting also an examination of the quality of site measurements. A series of model sensitivity tests has shown that DSR is primarily sensitive to cloud parameters, namely cloud cover and optical depth, es-

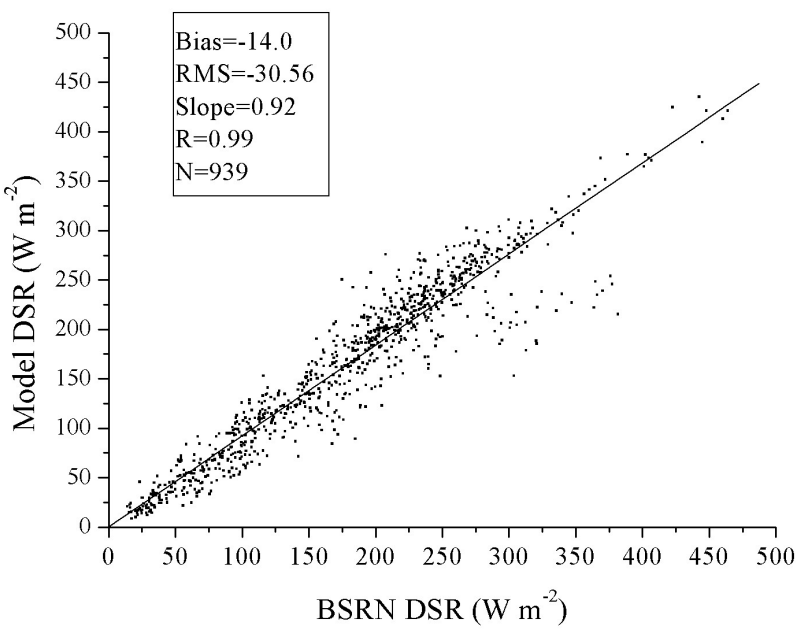

(b)

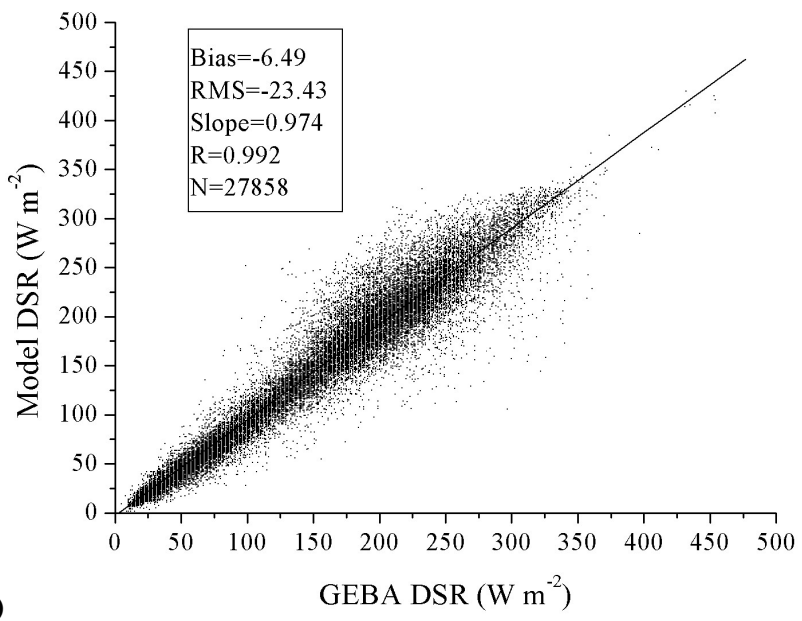

Fig. 9. Scatter plot comparison between model-computed and: (a) Baseline Surface Radiation Network (BSRN), and (b) Global Energy Balance Archive (GEBA) grid-cell data of monthly average downward shortwave radiation (DSR) at the Earth's surface, over the time periods 1992-2000 and 1984-2000, respectively. R and $\mathrm{N}$ are the correlation coefficient and number of matched data pairs, respectively.

pecially of low-level clouds, and secondarily to water vapour amount.

The 17-year model results indicate that the Earth's surface receives $171.6 \mathrm{Wm}^{-2}$, while it absorbs $149.4 \mathrm{Wm}^{-2}$, values that correspond to 50.2 and $43.7 \%$ of the incoming SW radiation at the top of the atmosphere. These values involve a long-term surface albedo equal to $12.9 \%$. According to our analysis, using either NCEP/NCAR or ECMWF humidity and temperature data in our model, has generally little effect on the computed DSR fluxes. Our computed value of $43.7 \%$ for the part of solar radiation that is absorbed by the Earth's surface, is smaller than the values given in previous studies, which are larger than $46 \%$. In combination with a long-term planetary albedo equal to $29.6 \%$ (Hatzianastassiou 
et al., 2004a), our modeling study indicates a partial absorption of solar radiation within the terrestrial atmosphere, equal to $26.7 \%$. Our values of 43.7 and $26.7 \%$ for the surface and atmospheric absorption of solar radiation, are significantly smaller and larger, respectively, than the corresponding values of about 50 and $20 \%$, estimated by earlier studies. Our value of $149.4 \mathrm{Wm}^{-2}$ for the net downward surface solar radiation, is smaller than the values given by other models and reanalysis projects, by at least $10-20 \mathrm{Wm}^{-2}$, except for versions 4 and 5 of ECHAM GCM, the ISCCP-FD fluxes (Zhang et al., 2004), and the ECMWF reanalysis. It is very interesting that our model computed value is very close to the revised "best" estimate of about $150 \mathrm{Wm}^{-2}$ from surface measurements. Comparable DSR and net DSR fluxes were computed for the northern and southern hemispheres.

The linear regression analysis applied to 204 global averages of monthly mean DSR fluxes, reveals a significant decadal increase in SW radiation reaching the Earth's surface, equal to $2.4 \mathrm{Wm}^{-2}$, associated with a corresponding decadal increase in surface solar absorption of $2.2 \mathrm{Wm}^{-2}$, over the 17-year period 1984-2000. The performed analysis has shown that the increasing surface solar heating, indicated by positive DSR and net DSR anomalies, started after the year 1992, and that it has been caused by a significant reduction in cloudiness during the last decade of 20th century. In contrast, mainly negative anomalies are found from 1984 through the early 1990s. Our results are in agreement with surface observations (Wild et al., 2005), also indicating an increase in DSR starting after 1990. A further analysis has demonstrated that the reduction in low-level cloud amounts, accounts for about $70 \%$ of the computed increasing trend in DSR. This is consistent with the results of a sensitivity study, showing that the surface SW radiative fluxes are primarily sensitive to cloud parameters, and more specifically to low, middle, and high-level cloud cover (in that order), and secondarily to other parameters, such as total precipitable water.

In the future, it is desirable to use more advanced models to make such computations of SRB using the same or similar input data. This can improve the accuracy of the results, though it involves other problems, for example greatly increasing computing time, which constitutes a problem in case of global scale studies. Further work is undertaken in order to increase the spatial and temporal resolution of the performed study, providing SRB fluxes at $1^{\circ}$ by $1^{\circ}$ latitudelongitude resolution or on a daily mean basis. Preliminary results show that there is good agreement with the ISCCPD2 based monthly mean $2.5^{\circ}$ resolution fluxes shown here. It is very important to perform validations of computed SRB fluxes on as long as possible time periods, since SRB changes with time.

Acknowledgements. This research was funded by the European Commission (contract: EVK2-CT-2000-00055) under the Thematic Programme: Preserving the Ecosystem; Key Action 2: Global Change, Climate and Biodiversity. The ISCCP-D2 and ISLSCP data were obtained from the NASA Langley Research
Center (LaRC) Atmospheric Sciences Data Center (ASDC). The NCEP/NCAR Global Reanalysis Project data were obtained from the National Oceanic and Atmospheric Administration (NOAA) Cooperative Institute for Research in Environmental Sciences (CIRES) Climate Diagnostics Center, Boulder, Colorado, USA. The ERA-15 ECMWF data were obtained from the Data Ordering Service of ECMWF. The GADS data were obtained from the Meteorological Institute of the University of Munich, Germany (http://www.meteo.physik.uni-muenchen.de/strahlung/aerosol/ aerosol.htm). The BSRN data were obtained from the BSRN database of the World Radiation Moniroring Center (WRMC) at Eidgenössische Technische Hochschule (ETH). The GEBA data were obtained from the GEBA database of the World Climate Progam - Water (WMO/ICSU) at ETH.

Edited by: L. M. Frohn

\section{References}

Briegleb, B. P., Minnis, P., Ramanathan, V., and Harrison, E.: Comparison of regional clear-sky albedos inferred from satellite observations and model computations, J. Clim. Appl. Meteor., 25, 214-226, 1986.

Cess, R. D., Dutton, E. G., DeLuisi, J. J., and Jiang, F.: Determining surface solar absorption from broadband satellite measurements for clear skies: Comparison with surface measurements, J. Climate, 4, 236-247, 1991.

Cess, R. D., Zhang, M. H., Minnis, P., et al.: Absorption of solar radiation by clouds: Observations versus models, Science, 267, 496-499, 1995.

Chen, C.-T. and Roeckner, E.: Validation of the Earth radiation budget as simulated by the Max Planck Institute for Meteorology general circulation model ECHAM4 using satellite observations of the Earth Radiation Budget Experiment, J. Geophys. Res., 101, 4269-4287, 1996.

Chen, J., Carlson, B. E., and Del Genio, A. D.: Evidence for strengthening of the tropical general circulation in the 1990s, Science, 295, 838-841, 2002.

Darnell, W. L., Staylor, W. F., Gupta, S. K., and Denn, F. M.: Estimation of surface insolation using Sun-synchronous satellite data, J. Climate, 1, 820-835, 1988.

Darnell, W. L., Staylor, W. F., Gupta, S. K., Ritchey, N. A., and Wilber, A. C.: Seasonal variation of surface radiation budget derived from International Satellite Cloud Climatology Project C1 data, J. Geophys. Res., 97, 15 741-15 760, 1992.

Del Genio, A. D., Yao, M.-S., Kovari, W., and Lo, K. K.-W.: A prognostic cloud water parameterization for global climate models, J. Climate, 9, 270-304, 1996.

Dickinson, R., Henderson-Sellers, R., and Kennedy, P.: BiosphereAtmosphere Transfer Scheme (BATS) Version 1e as cloupled to the NCAR Community Climate Model, Tech. Note NCAR/TN387+STR, Natl. Cent. For Atmos. Res., Boulder, Colo., 72 pp., 1993.

Ebert, E. E. and Curry, J. A.: A parameterization of ice cloud optical properties for climate models, J. Geophys. Res., 97, 3831-3836, 1992.

Esbensen, S. K. and Kushnir, Y.: The heat budget of the global oceans: An atlas based on surface marine observations, Rep. 29, Clim. Res. Inst., Oreg. State Univ., Corvallis, 1981. 
Fotiadi, A., Hatzianastassiou, N., Matsoukas, C., Pavlakis, K. G., Drakakis, E., Hatzidimitriou and Vardavas, I.: Analysis of the decrease in the tropical mean outgoing shortwave radiation at the top of atmosphere for the period 1984-2000, Atmos. Chem. Phys., 5, 1721-1730, 2005,

SRef-ID: 1680-7324/acp/2005-5-1721.

Fowler, L. D. and Randal, D. A.: Liquid and ice cloud microphysics in the CSU general circulation model. Part II: Impact of cloudiness, the earth's radiation budget, and the general circulation of the atmosphere, J. Climate, 9, 530-560, 1996.

Garratt, J. R.: Incoming shortwave fluxes at the surface - A comparison of GCM results with observations, J. Clim., 7, 72-80, 1994.

Garratt, J. R., Prata, A. J., Rotstayn, L. D., McAvaney, B. J., and Cusack, S.: The surface radiation budget over oceans and continents, J. Clim., 11, 1951-1968, 1998.

Gilgen, H. and Ohmura, A.: The Global Energy Balance Archive, Bull. Am. Meteor. Soc., 80, 831-850, 1999.

Gilgen, H., Wild, M., and Ohmura, A.: Means and trends of shortwave irradiance at the surface estimated from Global Energy Balance Archive, J. Climate, 11, 2042-2061, 1998.

Gupta, S. K., Ritchey, N. A., Wilber, A. C., Whitlovk, C. H., Gibson, G. G., and Stackhouse Jr., P. W.: A climatology of surface radiation budget derived from satellite data, J. Clim., 12, 2691$2710,1999$.

Hartmann, D. L.: Aerosol-Cloud-Climate Interactions, Radiative effects of clouds on Earth's climate, International Geophysics Series, vol. 54, P. Hobbs, Acad. Press Inc., 151-173, 1993.

Hartmann, D. L.: Global Physical Climatology, Academic Press, 411 pp., 1994.

Hatzianastassiou, N. and Vardavas, I.: Shortwave radiation budget of the Northern Hemisphere using International Satellite Cloud Climatology Project and NCEP/NCAR climatological data, J. Geophys. Res., 104, 24 401-24 421, 1999.

Hatzianastassiou, N. and Vardavas, I.: Shortwave radiation budget of the Southern Hemisphere using ISCCP C2 and NCEP/NCAR climatological data, J. Clim., 14, 4319-4329, 2001.

Hatzianastassiou, N., Fotiadi, A., Matsoukas, C., Drakakis, E., Pavlakis, K. G., Hatzidimitriou, N., and Vardavas, I.: Long-term global distribution of Earth's shortwave radiation budget at the top of atmosphere, Atmos. Chem. Phys., 4, 1217-1235, 2004a, SRef-ID: 1680-7324/acp/2004-4-1217.

Hatzianastassiou, N., Katsoulis, B., and Vardavas, I.: Global distribution of aerosol direct radiative forcing in the ultraviolet and visible arising under clear skies, Tellus, 56B, 51-71, 2004b.

Hatzidimitriou, D., Vardavas, I., Pavlakis, K., Hatzianastassiou, N., Matsoukas, C., and Drakakis, E.: On the decadal increase in the tropical mean outgoing longwave radiation for the period 19842000, Atmos. Chem. Phys., 4, 1419-1425, 2004,

SRef-ID: 1680-7324/acp/2004-4-1419.

Henderson-Sellers, A. and Wilson, M. F.: Surface albedo data for climate modelling, Rev. Geophys., 21, 1743-1778, 1983.

Hinkelman, L. M., Ackerman, T. P., and Marchand, R. T.: An evaluation of NCEP Eta model predictions of surface energy budget and cloud properties by comparison with measured ARM data, J. Geophys. Res., 104, 19535-19549, 1999.

Intergovernmental Panel on Climate Change (IPCC): Climate Change 2001, The Scientific Basis, 881 pp., edited by: Houghton J. T., Ding, Y., Griggs, D. J., et al., Cambridge Univ. Press, New
York, 2001.

Kiehl, J. T. and Trenberth, K. E.: Earth's annual global mean energy budget, Bull. Am. Meteorol. Soc., 78, 197-208, 1997.

Kiehl, J. T., Hack, J. J., Zhang, M. H., and Cess, R. D.: Sensitivity of a GCM climate to enhanced shortwave cloud absorption, J. Clim., 8, 2200-2212, 1995.

Kondratyev, K. Y.: Radiation Characteristics of the Atmosphere and the Earth's surface, Amerind., SNew Delhi, 580 pp., 1973.

Koepke, P., Hess, M., Schult, I., and Shettle, E. P.: Global aerosol data set, Rep. No. 243, Max-Planck Institut für Meteorologie, 44 pp., Hamburg, Germany, 1997.

Kuhn, M. H.: The role of land ice and snow in climate, in: Understanding Climate Change, Geophys. Monogr. Ser., vol. 52, edited by: Berger, A., Dickinson, R. E., and Kidson, J. W., pp. 17-28, American Geophysical Union, Washington, D.C., 1989.

Kyle, H. L., Mecherikunnel, A., Ardanuy, P., Lanning, P., Groveman, B., Garret-Gampbell, G., and Vonder Haar, T. H.: A comparison of two major earth radiation budget data sets, J. Geophys. Res., 95, 9951-9970, 1990.

Li, Z. and Leighton, H. G.: Global climatologies of solar radiation budgets at the surface and in the atmosphere from 5 years of ERBE data, J. Geophys. Res., 98, 4919-4930, 1993.

Li, Z., Barker, H. W., and Moreau, L.: The variable effect of clouds on atmospheric absorption of solar radiation, Nature, 376, 486490, 1995.

Li, Z., Moreau, L., and Arking, A.: On solar energy disposition: A perspective from observation and modelling, Bull. Am. Meteorol. Soc., 78, 53-70, 1997.

Liepert, B. G.: Observed reductions of surface solar radiation at sites in the United States and worldwide from 1961 to 1990, Geophys. Res. Lett., 29(12), doi:10.1029/2002GL014910, 2002.

Liou, K. N.: Radiation and cloud processes in the atmosphere. Theory, Observation and Modelling, Oxford University Press Inc., 487 pp., 1992.

Liou, K. N.: An introduction to atmospheric radiation, International Geophysics Series, Vol. 84, Academic Press, 583 pp., 2002.

Ohmura, A. and Gilgen, H.: Re-evaluation of the global energy balance. Interactions between global climate subsystems: The legacy of Hann, Geophys. Monogr., No. 75, International Union of Geodesy and Geophysics, 93-110, 1993.

Ohmura, A., Gilgen, H., Hegner, H., Mueller, G., Wild, M., Dutton, E. G., Forgan, B., Froehlich, C., Philippona, R., Heimo, A., Koenig-Langlo, G., McArthur, B., Pinker, R., Whitlock, C. H., and Dehne, K.: Baseline Surface Radiation Network (BSRN/WCRP): New precision radiometry for climate research, Bull. Am. Meteorol. Soc., 79, 2115-2136, 1998.

Peixoto, J. P. and Oort, A. H.: Physics of Climate, Springer, N.Y., 520 pp., 1992.

Peng, L. I., Chou, M.-D., and Arking, A.: Climate studies with a multi-layer energy balance model. Part I: Model description and sensitivity to the solar constant, J. Atmos. Sci., 39, 2639-2656, 1982.

Pilewski, P. and Valero, F.: Direct observations of excess solar absorption by clouds, Science, 257, 1626-1629, 1995.

Pinker, R. T. and Laszlo, I.: Modelling surface solar irradiance for satellite applications on a global scale, J. Appl. Meteorol., 31, 194-211, 1992.

Pinker R. T., Zhang, B., and Dutton E. G.: Do satellites detect trends in surface solar radiation?, Science, 308, 850-854, 2005. 
Ramanathan, V.: Scientific use of surface radiation budget for climate studies. Surface Radiation Budget for Climate Applications, NASA PR-1169, 58-86, 1986.

Ramanathan, V.: The role of Earth Radiation Budget studies in climate and general circulation research, J. Geophys. Res., 40754094, 1987.

Ramanathan, V., Subasilar, B., Zhang, G. J., Conant, W., Cess, R. D., Kiehl, J. T., Grassl, H., and Shi, L.: Warm pool heat budget and shortwave cloud forcing: S missing physics, Science, 267, 499-503, 1995.

Raschke, E., Gratzki, A., and Rieland, M.: Estimates of global radiation at the ground from the deduced data sets of the International Cloud Climatology Project, J. Climatol., 7, 205-213, 1987.

Roesch, A., Wild, M., Gilgen, H., and Ohmura, A.: A new snow cover fraction parameterization for the ECHAM4 GCM, Clim. Dyn., 17, 933-946, 2001.

Roesch, A., Wild, M., Pinker, R., and Ohmura, A.: Comparison of surface spectral albedos and their impact on the general circulation model estimated surface climate, J. Geophys. Res., 107(D14), doi:10.1029/2001JD000809, ACL 13-1-ACL 13-8, 2002.

Rossow, W. B. and Lacis, A. A.: Global, seasonal cloud variations from satellite radiance measurements. Part II: Cloud properties and radiative effects, J. Clim., 3, 1204-1253, 1990.

Rossow, W. B. and Zhang, Y.-C.: Calculation of surface and top of atmosphere radiative fluxes from physical quantities based on ISCCP data sets 2. Validation and first results, J. Geophys. Res., 100, 1167-1197, 1995.

Rossow, W. B. and Schiffer, R. A.: Advances in understanding clouds from ISCCP, Bull. Am. Meteorol. Soc., 80, 2261-2287, 1999.

Rossow, W. B., Walker, A. W., Beuschel, D. E., and Roiter, M. D.: International Satellite Cloud Climatology Project (ISCCP). Documentation of new cloud datasets, 115 pp., Wold Meteorol. Org. Geneva, 1996.

Schmetz, J.: Towards a surface radiation climatology: Retrieval of downward irradiance from satellites, Atmos. Res., 23, 287-321, 1989.

Slingo, A.: A GCM parameterization for the shortwave radiative properties of water clouds, J. Atmos. Sci., 46, 1419-1427, 1989.

Stephens, G. L.: Optical properties of eight water cloud types, Tech. Pap. 36, CSIRO Div. of Atmos. Phys., 254 pp., 1979.

Stephens, G. L. and Greenwald, T. J.: The earth's radiation budget and its relation to atmospheric hydrology, 2, Observations of cloud effects, J. Geophys. Res., 96, 15 325-15 340, 1991.

Stackhouse Jr., P. W., Cox, S. T., Gupta, S. K., Dipasquale, R. C., and Brown, D. R.: The WCRP/GEWEX Surface Radiation Budget Project Release 2: First results at 1 degree resolution. Preprints, 10th Conf. on Atmospheric Radiation: A Symp. With Tributes to the Works of Verner Suomi. Madison, WI, Am. Meteorol. Soc., 520-523, 1999.

Stackhouse Jr., P. W., Cox, S. J., Gupta, S. K., Chiacchio, M., and Mikovitz, J. C.: The WCRP/GEWEX surface radiation budget project release 2: An assessment of surface fluxes at 1 degree resolution. International Radiation Sysposium, St. Petersburg, Russia, 24-29 July 2000, IRS 2000: Current Problems in Atmospheric Radiation, edited by: Smith, W. L. and Timofeyev, Y., A. Deepak Publishing, 147, 2001.

Stanhill, G. and Cohen, S.: Global dimming: A review of the evi- dence for a widespread and significant reduction in global radiation with discussion of its probable causes and possible agricultural consequences, Agricult. Forest. Meteorol., 107, 255-278, 2001.

Suttles, J. T. and Ohring, G.: Surface radiation budget for climate applications, NASA Reference Publication 1169, NASA, Washington D.C., 132 pp., 1986.

Thekaekara, M. P. and Drummond, A. J.: Standard values for the solar constant and its spectral components, Nature Phys. Sci., 229, 6-9, 1971.

Torres, O., Barthia, P. K., Herman, J. R., Sinyuk, A., Ginoux, R., and Holben B.: A long-term record of aerosol optical depth from TOMS observations and comparison to AERONET measurements, J. Atmos. Sci., 59, 398-413, 2002.

Vardavas, I. and Carver, J. H.: Solar and terrestrial parameterizations for radiative convective models, Planet. Space Sci., 32, 1307-1325, 1984.

Vardavas, I. M. and Koutoulaki, K.: A model for the solar radiation budget of the Northern Hemisphere: Comparison with Earth Radiation Budget Experiment data, J. Geophys. Res., 100, 73037314, 1995.

Weare, B.-C.: Relationships between net radiation at the surface and the top of atmosphere derived from a general circulation model, J. Clim., 2, 193-197, 1989.

Wei, X., Hahmann, A. N., Dickinson, R. E., et al.: Comparison of albedos computed by land surface models and evaluation against remotely sensed data, J. Geophys. Res., 106, 20 687-20 702, 2001.

Whitlock, C. H., Charlock, T. P., Staylor, W. F., et al.: First global WCRP shortwave surface radiation budget dataset, Bull. Amer. Meteor. Soc., 76, 905-922, 1995.

Wielicki, B. A., Wong, T. M., Allan, R. P., et al.: Evidence for large decadal variability in the tropical mean radiative energy budget, Science, 295, 841-844, 2002.

Wild, M.: Solar radiation budgets in atmospheric model intercomparison from surface perspective, Geophys. Res. Lett., 32, L07704, doi:10.1029/2005GL022421, 2005.

Wild, M. and Ohmura, A.: The role of clouds and the cloud-free atmosphere in the problem of underestimated absorption of solar radiation in GCM atmospheres, Phys. Chem. Earth, 24B, 261268, 1999.

Wild, M., Ohmura A., Gilgen H., and Roeckner E.: Validation of general circulation model radiative fluxes using surface observations, J. Clim., 8, 1309-1324, 1995.

Wild, M., Ohmura A., Gilgen H., Roeckner E., Giorgetta M., and Morcrette J.-J: The disposition of radiative energy in the global climate system: GCM-calculated versus observational estimates, Clim. Dyn., 14, 853-869, 1998a.

Wild, M., Ohmura, A., Gilgen, H., and Morcrette, J.-J: The distribution of solar energy at the Earth's surface as calculated in the ECMWF Re-analysis, Geophys. Res. Lett., 25, 23, 4373-4376, 1998 b.

Wild, M., Ohmura A., Gilgen, H., and Rosenfeld, D.: On the consistency of trends in radiation and temperature records and implications for the global hydrological cycle, Geophys. Res. Lett., 31, L11201, doi:10.1029/2003GL019188, 2004.

Wild, M., Gilgen, H., Roesch, A., et al.: From dimming to brightening: decadal changes in solar radiation at Earth's surface, Science, 308, 847-850, 2005. 
Wittmeyer, I. L. and Vonder Haar, T. H.: Analysis of the global ISCCP TOVS water vapor climatology, J. Clim., 8, 325-333, 1994.

Yu, R., Zhang, M., and Cess, R. D.: Analysis of the atmospheric energy budet: A consistency study of available data sets, J. Geophys. Res., 108, 9655-9661, 1999.
Zhang, Y.-C., Rossow, W. B., Lacis, A. A., Oinas V., and Mishchenko, M. I.: Calculation of radiative fluxes from the surface to top-of-atmosphere based on ISCCP and other global datasets: Refinements of the radiative transfer model and the input data, J. Geophys. Res., 109, D19105, doi:10.1029/2003JD004457, 2004. 